\title{
Progress on Fabrication of Planar Diffusion Couples with Representative TRISO PyC/SiC Microstructure
}

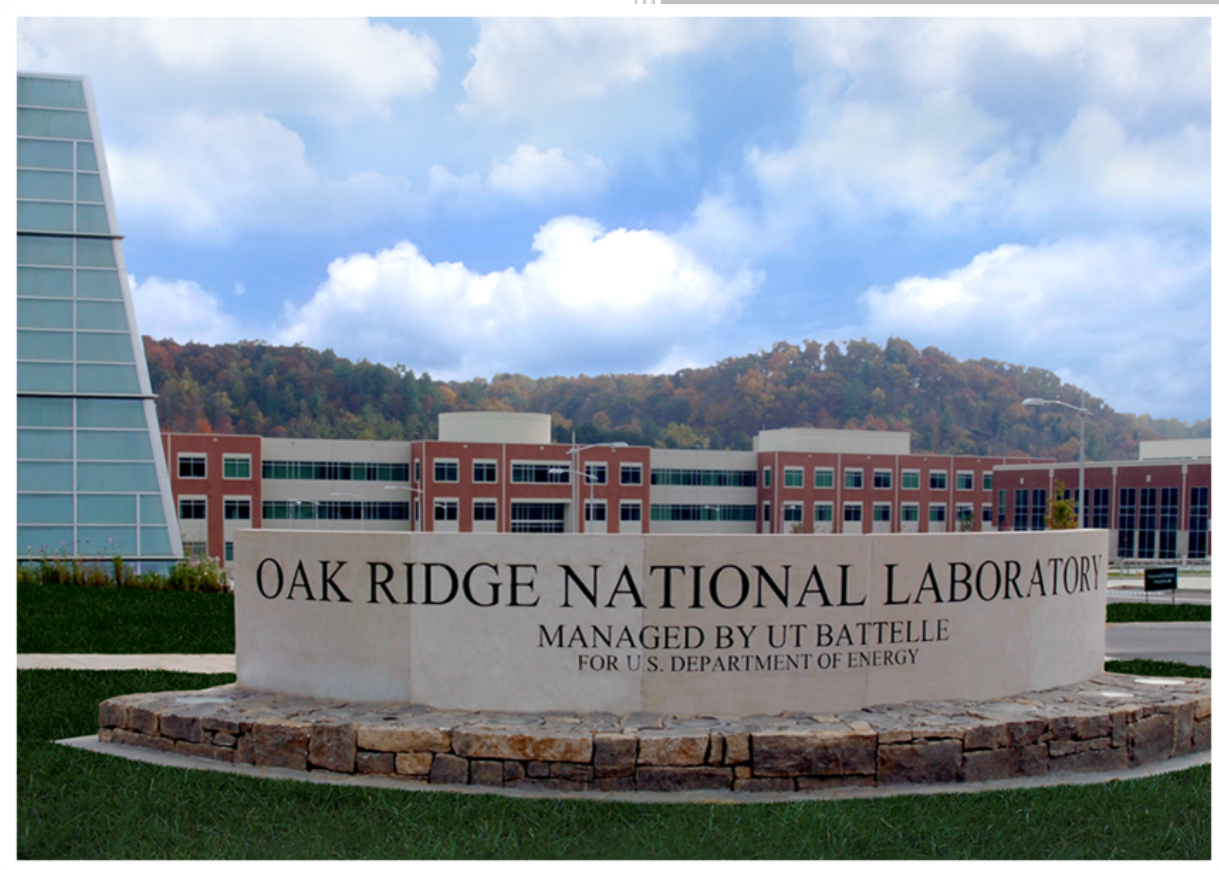

Approved for public release. Distribution is unlimited.
Tyler J. Gerczak Anne A. Campbell John D. Hunn Brian C. Jolly Austin T. Schumacher

October 2017 


\title{
DOCUMENT AVAILABILITY
}

Reports produced after January 1, 1996, are generally available free via US Department of Energy (DOE) SciTech Connect.

Website http://www.osti.gov/scitech/

Reports produced before January 1, 1996, may be purchased by members of the public from the following source:

\author{
National Technical Information Service \\ 5285 Port Royal Road \\ Springfield, VA 22161 \\ Telephone 703-605-6000 (1-800-553-6847) \\ TDD 703-487-4639 \\ Fax 703-605-6900 \\ E-mail info@ntis.gov \\ Website http://www.ntis.gov/help/ordermethods.aspx
}

Reports are available to DOE employees, DOE contractors, Energy Technology Data Exchange representatives, and International Nuclear Information System representatives from the following source:

Office of Scientific and Technical Information

PO Box 62

Oak Ridge, TN 37831

Telephone 865-576-8401

Fax 865-576-5728

E-mail reports@osti.gov

Website http://www.osti.gov/contact.html

This report was prepared as an account of work sponsored by an agency of the United States Government. Neither the United States Government nor any agency thereof, nor any of their employees, makes any warranty, express or implied, or assumes any legal liability or responsibility for the accuracy, completeness, or usefulness of any information, apparatus, product, or process disclosed, or represents that its use would not infringe privately owned rights. Reference herein to any specific commercial product, process, or service by trade name, trademark, manufacturer, or otherwise, does not necessarily constitute or imply its endorsement, recommendation, or favoring by the United States Government or any agency thereof. The views and opinions of authors expressed herein do not necessarily state or reflect those of the United States Government or any agency thereof. 


\title{
PROGRESS ON FABRICATION OF PLANAR DIFFUSION COUPLES WITH REPRESENTATIVE TRISO PYC/SIC MICROSTRUCTURE
}

\author{
Tyler J. Gerczak \\ Anne A. Campbell \\ John D. Hunn \\ Brian C. Jolly \\ Austin T. Schumacher
}

Date Published: October 2017

\author{
Prepared by \\ OAK RIDGE NATIONAL LABORATORY \\ Oak Ridge, TN 37831-6283 \\ managed by \\ UT-BATTELLE, LLC \\ for the \\ US DEPARTMENT OF ENERGY \\ under contract DE-AC05-00OR22725
}





\section{CONTENTS}

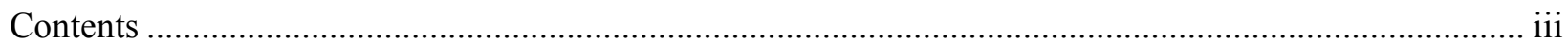

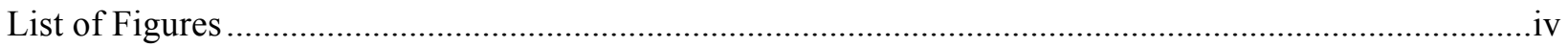

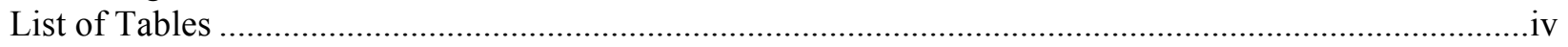

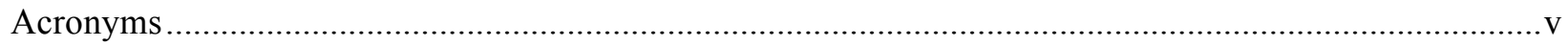

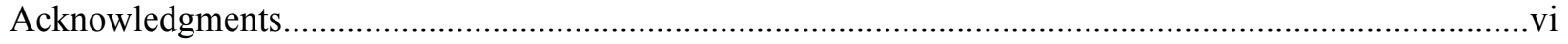

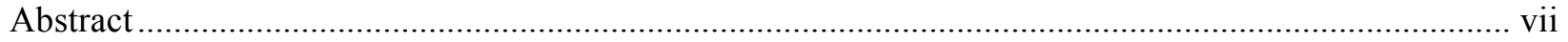

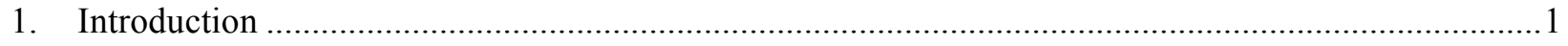

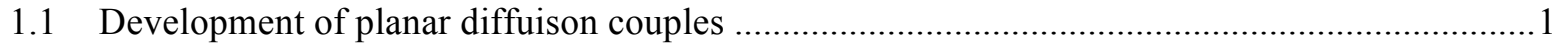

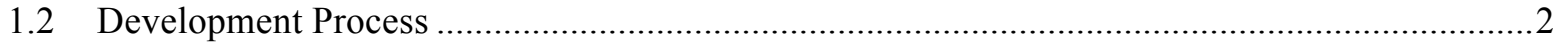

1.2.1 Criteria for design................................................................................

1.2.2 Fabrication Approach .........................................................................

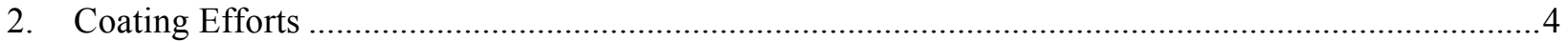

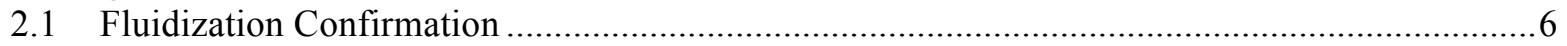

2.2 Full coating Deposition ........................................................................................

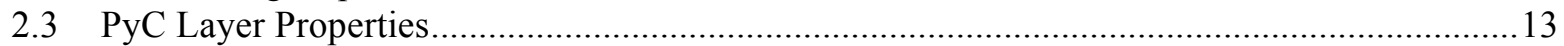

2.3.1 Supplemental PyC Analysis ........................................................................ 17

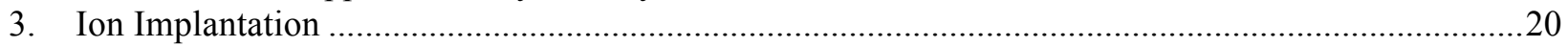

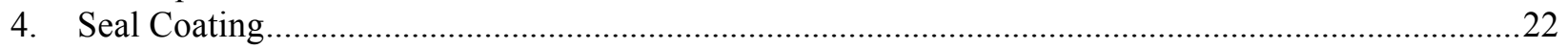

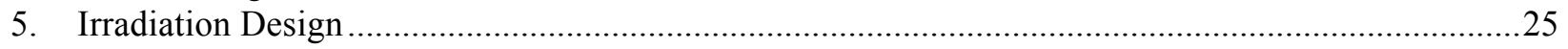

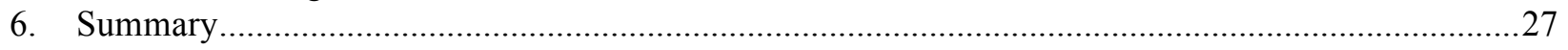

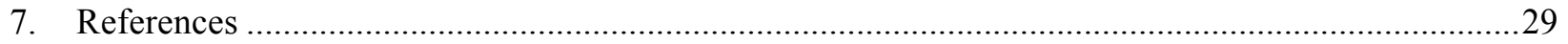




\section{LIST OF FIGURES}

Figure 1. Schematic of diffusion couple fabrication process.................................................................

Figure 2. Schematic cutaway of the FBCVD equipment used for the diffusion couple coating development work.....

Figure 3. Image of (a) various uncoated sapphire discs and (b) $\mathrm{PyC} / \mathrm{SiC} / \mathrm{PyC}$ coated 9-mm-diameter, 0.5

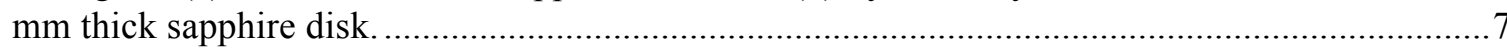

Figure 4. Optical micrographs of (a) center and (b) edge and adjacent area of a thick, 9-mm-diameter $\mathrm{PyC} / \mathrm{SiC} / \mathrm{PyC}$ coated sapphire disk (DCCD-02) ..............................................................

Figure 5. Example chipping of the coating and substrate during fluidization from a thick, 9-mm-diameter

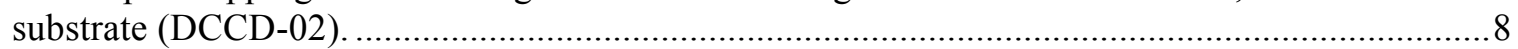

Figure 6. Sectioned $\mathrm{PyC} / \mathrm{SiC}$ diffusion couple specimens from DCCD-03 ...........................................

Figure 7. Optical image of the PyC/SiC/PyC layers of (a) DCCD-04 and (b) DCCD-06........................10

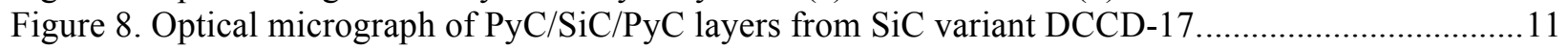

Figure 9. EBSD analysis of DCCD-17 showing IQ and IPF maps of SiC layer adjacent to PyC..............12

Figure 10. PyC density as a function of coating temperature for first series of interrupted coatings, the

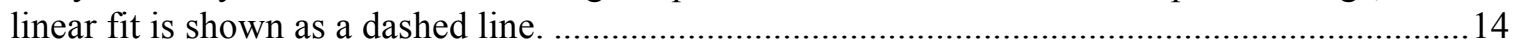

Figure 11. Oxidized graphite furnace element and replacement element for fluidized bed-coater.............15

Figure 12. PyC density as a function of coating temperature for first (red squares) and second (green circles) series of interrupted PyC coatings the polynomial fits are shown as dotted lines. The estimated upper bound of DCCD-15I is shown as an unfilled green circle with the polynomial fit

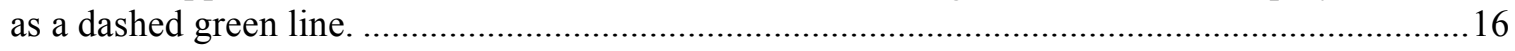

Figure 13. Optical images of (a) and inclined polished sample and (b) cross-section polished sample. ....18

Figure 14. Analysis of inclined polished sample showing (a) an overview optical image with location of 2-MGEM scan, (b) intensity map, (c) diattenuation map, and (d) fast axis angle map.................19

Figure 15. 3D representations of different components of the PyC/SiC interface from DCCD-04; (a) PyC,

(b) $\mathrm{SiC}$, and (c) open volume, with the reconstructed volume shown in (d) ................................20

Figure 16. DCCD-06 samples loaded in the $\mathrm{Cu}$ holder on the in-line implanter at MIBL........................21

Figure 17. Estimated depth profile for $400 \mathrm{kV}, 4.2 \times 10^{16}$ ions $/ \mathrm{cm}^{2} \mathrm{Ag}^{+}$implantation.................................22

Figure 18. Optical image of DCCD-04-SC2 subjected to $900^{\circ} \mathrm{C}$ for 5 hours. ........................................24

Figure 19. Optical images of the samples after the burn and remaining in the deposited material at the

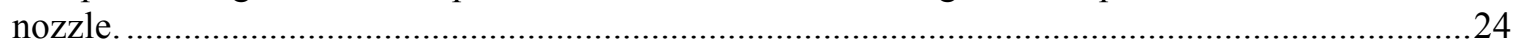

Figure 20. Section view of capsule design and components, reproduced from Petrie et.al. [28]...............26 Figure 21. Thermal analysis results showing temperature contour profiles for (a) the internal components,

(b) specimens, and (c) $\mathrm{SiC}$ temperature monitors, reproduced from Petrie et.al. [28]. .27

\section{LIST OF TABLES}

Table 1. Test matrix for diffusion couple study.

Table 2. Properties of AGR-2 UCO fuel variant and the three planar diffusion couple variants in this study

Table 3. Typical gas mixtures and temperatures used for $\mathrm{PyC}$ and $\mathrm{SiC}$ deposition. .................................5

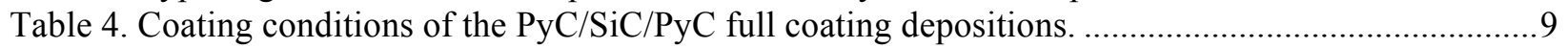

Table 5. Average layer thicknesses for full $\mathrm{PyC} / \mathrm{SiC} / \mathrm{PyC}$ coating runs...............................................11

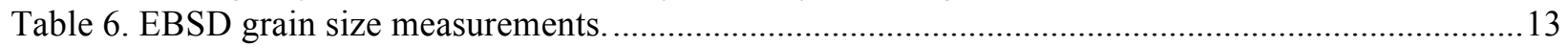

Table 7. Coating conditions of the first series of PyC only interrupted runs............................................13

Table 8. Coating conditions of the second series of PyC only interrupted runs....................................... 16

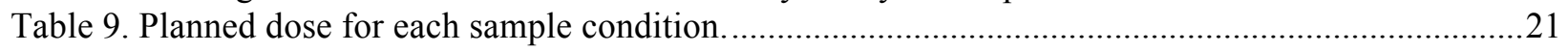

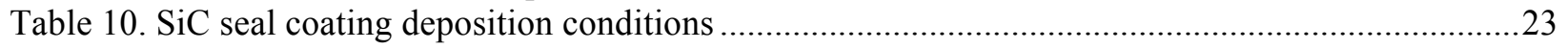




\section{ACRONYMS}

2-MGEM Two-Modulator Generalized Ellipsometry Microscope

AGR

AGR-1

AGR-2

CGF

CVD

dpa

Advanced Gas Reactor (Fuel Development and Qualification Program)

EBSD

FBCVD

HFIR

IPF

IQ

LIBS

MIBL

MTS

First AGR fuel irradiation experiment

Second AGR fuel irradiation experiment

Coating gas fraction

Chemical vapor deposition

NEUP

OPTAF

Displacements per atom

Electron backscatter diffraction

ORNL

PIE

PyC

S-PyC

sccm

Fluidized bed chemical vapor deposition

High Flux Isotope Reactor

Inverse pole figure

Image quality

Laser induced breakdown spectroscopy

Michigan Ion Beam Laboratory

Methyltrichlorosilane

Nuclear Energy University Program

Optical anisotropy factor

Oak Ridge National Laboratory

Post-irradiation examination

Pyrolytic carbon or pyrocarbon

Support pyrocarbon

$\mathrm{SiC}$

Standard cubic centimeters per minute

TRISO

Silicon carbide (TRISO layer)

UCO

Tristructural-isotropic (coated particles)

mixed uranium carbide/uranium oxide (kernels) 


\section{ACKNOWLEDGMENTS}

This research is being performed using funding received from the DOE Office of Nuclear Energy's Nuclear Energy University Program through a joint NEET/NEUP R\&D with NSUF access award (Project 16-10764). Significant support for this work was provided by Victoria Cox, John Dyer, J. David ArreguiMena, and Tom Geer. 


\begin{abstract}
Release of fission products from tristructural-isotropic (TRISO) coated particle fuel limits the fuel's operational lifetime and creates potential safety and maintenance concerns. A need for diffusion analysis in representative TRISO layers exists to provide fuel performance models with high fidelity data to improve fuel performance and efficiency. An effort has been initiated to better understand fission product transport in, and release from, quality TRISO fuel by investigating diffusion couples with representative pyrocarbon $(\mathrm{PyC})$ and silicon carbide $(\mathrm{SiC})$. Here planar $\mathrm{PyC} / \mathrm{SiC}$ diffusion couples are being developed with representative $\mathrm{PyC} / \mathrm{SiC}$ layers using a fluidized bed chemical vapor deposition (FBCVD) system identical to those used to produce laboratory-scale TRISO fuel for the Advanced Gas Reactor Fuel Qualification and Development Program's (AGR) first fuel irradiation. The diffusivity in the PyC/SiC of silver, silver and palladium as a system, europium, and strontium will be studied at elevated temperatures and under high temperature neutron irradiation. The study also includes a comparative study of PyC/SiC diffusion couples with varying TRISO layer properties to understand the influence of $\mathrm{SiC}$ microstructure (grain size) and the $\mathrm{PyC} / \mathrm{SiC}$ interface on fission product transport. The first step in accomplishing these goals is the development of the planar diffusion couples. The diffusion couple construction consists of multiple steps which include fabrication of the primary $\mathrm{PyC} / \mathrm{SiC}$ structures with targeted layer properties, introduction of fission product species, and seal coating to create an isolated system. Coating development has shown planar $\mathrm{PyC} / \mathrm{SiC}$ diffusion couples with similar properties to AGR TRISO fuel can be produced. A summary of the coating development process, characterization methods, and status are presented.
\end{abstract}


ORNL/TM-2017/704-R0

viii 


\section{INTRODUCTION}

\subsection{DEVELOPMENT OF PLANAR DIFFUISON COUPLES}

Release of fission products from irradiated tristructural-isotropic (TRISO) fuel limits the fuel's operational lifetime and contributes to safety and maintenance concerns. Select fission products observed to be released through intact TRISO layers include silver, europium, and strontium [1]. The release of silver has received significant interest in the scientific community because of the variable release behavior and lack of consensus regarding release mechanism [2-4]. The influence of a cooperative mechanism for silver release with palladium have also been postulated by Olivier and Neethling [5], [6]. The release of strontium is of interest particularly because it is biologically relevant, while europium release is radiologically relevant for fuel qualification efforts because the release is a significant contributor to the radiation observed outside of the TRISO containment [1].

To improve fuel performance a better understanding of the diffusion of fission products in representative TRISO-layer pyrocabon (PyC) and silicon carbide ( $\mathrm{SiC})$ systems is needed. Planar diffusion couples are being developed at Oak Ridge National Laboratory (ORNL) to determine diffusion coefficients for select fission product species and systems $(\mathrm{Ag}, \mathrm{Ag}+\mathrm{Pd}, \mathrm{Sr}, \mathrm{Eu})$ in a $\mathrm{SiC}$ layer that is representative of the $\mathrm{SiC}$ in the TRISO coated particle fuel system. The effort focuses on exploring the influence of neutron irradiation on the diffusion kinetics in $\mathrm{SiC}$ as well as complimentary thermally-driven diffusion. For silver in particular, the study of the influence of neutron irradiation is vital to better understand the large discrepancy between diffusion coefficients determined from in-pile, out-of-pile, and surrogate diffusion couple experiments [6-19]. Layer property variables are also being explored to determine the influence of the $\mathrm{SiC}$ microstructure and the $\mathrm{PyC} / \mathrm{SiC}$ interface on fission product uptake and transport in the $\mathrm{SiC}$ layer. Through systematic study, this effort aims to provide new insight on fission product transport in representative TRISO layers leading to a more complete understanding of fission product release in real fuel systems. The measured diffusion kinetics will also be used to provide data to fuel performance models for safe and efficient high temperature gas cooled reactor operation.

The exploration of planar, representative PyC/SiC diffusion couples has some benefits over post-irradiation examination (PIE) of irradiated TRISO fuel systems as a result of a number of experimental constraints associated with PIE, irradiation, and the fuel geometry. In particular, the fission product evolution is complex in a fuel system. The complexity arises from fission product production being time dependent, coupled with observed variability of fission product stabilization and release from the fuel kernel. This complicated behavior results in difficulty in identifying the initial conditions and boundary conditions for diffusion analysis. The fuel also experiences variable, time-dependent thermal histories which further complicates analysis of the diffusion kinetics. An additional challenge is the high activity and spherical geometry of irradiated TRISO particles. These qualities limit access to modern depth profiling instrumentation which are necessary for determining diffusion profiles.

Successful exploration of a planar $\mathrm{C} / \mathrm{SiC}$ diffusion couple was first demonstrated by Dwaraknath and Was [20]. The current study builds off of this original concept by exploring representative $\mathrm{PyC} / \mathrm{SiC}$ diffusion couples. In this work, the $\mathrm{PyC} / \mathrm{SiC}$ layers are produced using a fluidized bed chemical vapor deposition (FBCVD) furnace with targeted properties found in TRISO fuel fabricated for the DOE Advanced Gas Reactor Fuel Qualification and Development program (AGR). By targeting the layer properties of AGR fuel to study representative $\mathrm{PyC}$ and $\mathrm{SiC}$, greater fidelity exists when comparing the diffusion results to data from the AGR PIE efforts concerning fission product release. Additionally, the planar geometry simplifies depth-profiling analysis and allows for sensitive depth profiling techniques to be utilized, such as Rutherford Backscatter Spectroscopy and Secondary Ion Mass Spectroscopy. 
As stated, the study includes two primary thrusts: exploration of the impact of neutron irradiation on diffusion kinetics and exploration of high temperature diffusion. Table 1 shows the proposed test matrix for the study. Both planned thrusts explore multiple diffusion couple variants, which include a Baseline, $\mathrm{SiC}$, and $\mathrm{PyC}$ variant, to explore the influence of layer properties on fission product transport. The inclusion of the "commercial $\mathrm{SiC}$ " variant provides context to studies reported in the literature that investigated diffusion in commercial CVD SiC. The neutron irradiation and thermal equivalent conditions will explore the impact of neutron irradiation on fission product diffusion. The neutron irradiations will be conducted in the High Flux Isotope reactor (HFIR) at ORNL. The ultimate irradiation temperature is limited by capsule design, while the two dose targets of 0.5 displacements per atom (dpa) and $1.0 \mathrm{dpa}$ were selected to show time and dose dependent evolution of diffusion profiles under neutron irradiation. The $0.5 \mathrm{dpa}$ and $1.0 \mathrm{dpa}$ conditions result in a fast neutron fluence equivalent of $5.0 \times 10^{24} \mathrm{n} / \mathrm{m}^{2}$ and $1.0 \times 10^{25} \mathrm{n} / \mathrm{m}^{2}(\mathrm{E}>0.18 \mathrm{MeV})$, respectively. The thermal equivalent condition serves as a control to determine the extent, if any, of neutron-radiation-enhanced diffusion at an average temperature of 1120 ${ }^{\circ} \mathrm{C}$. Note, the initial target temperature was $1100{ }^{\circ} \mathrm{C}$ with the average irradiation temperature of $1120{ }^{\circ} \mathrm{C}$ expected based on thermal analysis of the capsule design (see Section 5). The full set of diffusion couple variants are not planned to be included in the irradiation because of the limited space for specimens and a need for redundant specimens to ensure appropriate specimens are available for analysis after irradiation. Excess irradiated diffusion couples can be made available to the Nuclear Energy University Program (NEUP) materials archive for future analysis. The high temperature thermal diffusion conditions will explore diffusion at elevated temperature to determine kinetics and understand the influence of the layer variants on transport in the $\mathrm{PyC} / \mathrm{SiC}$ system. The high temperature results are also relevant to compare to the release of fission products observed during TRISO fuel safety testing at elevated temperatures [21].

Table 1. Test matrix for diffusion couple study.

\begin{tabular}{|c|c|c|c|}
\hline Description & Condition^ $^{\wedge}$ & Variants* & Exposure Time \\
\hline \multirow{2}{*}{$\begin{array}{l}\text { Neutron } \\
\text { Irradiation }\end{array}$} & $0.5 \mathrm{dpa}, 1120^{\circ} \mathrm{C}$ & \multirow{4}{*}{$\begin{array}{c}\text { Baseline: } \mathrm{Ag}, \mathrm{Ag}+\mathrm{Pd}, \mathrm{Eu}, \mathrm{Sr} \\
\text { SiC Variant: } \mathrm{Ag}, \mathrm{Eu}, \mathrm{Sr} \\
\text { Commercial } \mathrm{SiC}: \mathrm{Ag}\end{array}$} & $\sim 168 \mathrm{~h}$ \\
\hline & $1.0 \mathrm{dpa}, 1120^{\circ} \mathrm{C}$ & & $\sim 336 \mathrm{~h}$ \\
\hline \multirow{2}{*}{$\begin{array}{l}\text { Thermal } \\
\text { Equivalent }\end{array}$} & $\begin{array}{c}\text { Temp. and time equal to } \\
0.5 \text { dpa capsule }\end{array}$ & & $\sim 168 \mathrm{~h}$ \\
\hline & $\begin{array}{c}\text { Temp. and time equal to } \\
1.0 \text { dpa capsule }\end{array}$ & & $\sim 336 \mathrm{~h}$ \\
\hline \multirow{3}{*}{$\begin{array}{c}\text { High } \\
\text { Temperature } \\
\text { Thermal } \\
\text { Diffusion }\end{array}$} & $1500^{\circ} \mathrm{C}$ & \multirow{3}{*}{$\begin{array}{c}\text { Baseline: } \mathrm{Ag}, \mathrm{Ag}+\mathrm{Pd}, \mathrm{Eu}, \mathrm{Sr} \\
\text { PyC Variant: } \mathrm{Ag}, \mathrm{Ag}+\mathrm{Pd} \\
\text { SiC Variant: } \mathrm{Ag}, \mathrm{Ag}+\mathrm{Pd}, \mathrm{Eu}, \mathrm{Sr}\end{array}$} & \multirow{3}{*}{$150,300 \mathrm{~h}$} \\
\hline & $1600^{\circ} \mathrm{C}$ & & \\
\hline & $1700^{\circ} \mathrm{C}$ & & \\
\hline
\end{tabular}

*Excess samples will go to NEUP archive.

$\wedge^{\wedge}$ The estimated neutron irradiation temperature is based on capsule design thermal analysis.

\subsection{DEVELOPMENT PROCESS}

\subsubsection{Criteria for design}

The primary requirement of the diffusion couple design was to target the TRISO layer properties of the second AGR fuel irradiation (AGR-2) test fuel. The AGR-2 TRISO properties were similar to AGR-1 Variant 3, so process knowledge from the first AGR fuel irradiation (AGR-1) fuel fabrication was used to target the desired PyC/SiC microstructure. The AGR-2 properties provide a reference to an irradiated fuel system and also allow for potential relative comparisons to the AGR-2 PIE results. Beyond layer property targets, geometric considerations were taken into account for sample analysis and irradiation in the HFIR. 
Ultimately, a planar, rectangular geometry was selected based on the HFIR capsule design criteria developed (summarized in Section 5).

Prior experience provided confidence in the ability to deposit TRISO layers in planar geometries using an identical FBCVD coater to that which was used to coat AGR-1 TRISO particles. However, the change in geometry relative to spherical TRISO particles requires a research and development effort to dial in coating conditions to produce samples with the appropriate layer properties, as the same deposition conditions may not translate to the new geometry.

Targeted properties for the three diffusion couple variants (Baseline, PyC Variant, and SiC Variant) are listed in Table 2. The Baseline variant serves to represent typical PyC and SiC from AGR-2 TRISO fuel particles containing mixed uranium carbide/uranium oxide (UCO) kernels, whose targeted properties are defined by the AGR-2 fuel specification [22]. The exception is the $\mathrm{SiC}$ grain size target as the specification calls for the grain size to be smaller than a visible standard [22]. The targeted $\mathrm{SiC}$ grain sizes for all three variants are taken from the measured $\mathrm{SiC}$ grain sizes of TRISO batches from AGR-1 Variant 1 and AGR-2 UCO-TRISO [23]. These values serve as a measurable property targets for the PyC/SiC diffusion couple $\mathrm{SiC}$ layer.

The PyC variant targets an increased PyC density to reduce the interfacial stitching between the PyC/SiC interface. The exploration of the $\mathrm{PyC}$ variant serves to provide insight on the role of the interfacial structure on fission product interactions with the $\mathrm{SiC}$ layer. For the $\mathrm{PyC}$ variant, the $\mathrm{SiC}$ layer remains consistent with the Baseline variant but the PyC density is required to be above $1.95 \mathrm{~g} / \mathrm{cm}^{3}$, which is outside the AGR-2 specification. The SiC variant explores the influence of grain size on fission product transport as the $\mathrm{SiC}$ grain size has been shown to influence release of fission products in TRISO particles during safety testing $[21,23]$. The $\mathrm{SiC}$ variant will target the same PyC properties as the Baseline variant but present a larger grain size representative of the AGR-1 SiC variants that did not include argon dilution in the hydrogen/MTS deposition gases.

Table 2. Properties of AGR-2 UCO fuel variant and the three planar diffusion couple variants in this study.

\begin{tabular}{|c|c|c|c|}
\hline PyC Density & PyC Anisotropy & SiC Density & SiC Grain Size \\
\hline$\left(\mathrm{g} / \mathrm{cm}^{3}\right)$ & (OPTAF) & $\left(\mathrm{g} / \mathrm{cm}^{3}\right)$ & $\begin{array}{cc}\text { (major } & \text { (minor } \\
\text { axis, } \mu \mathrm{m}) & \text { axis, } \mu \mathrm{m})\end{array}$ \\
\hline
\end{tabular}

\begin{tabular}{ccccccc}
\hline $\begin{array}{c}\text { AGR-2 UCO TRISO } \\
\text { measured values [22, 23] }\end{array}$ & $1.890 \pm 0.011$ & $1.0236 \pm 0.0008$ & $3.197 \pm 0.004$ & $0.89 \pm 0.14$ & $0.35 \pm 0.05$ \\
\hline \multirow{3}{*}{ Targets } & Baseline & $1.90 \pm 0.05$ & $\leq 1.03$ & $\geq 3.19$ & $0.89 \pm 0.14$ & $0.35 \pm 0.05$ \\
\cline { 2 - 7 } & PyC Variant & $>1.95$ & $\leq 1.03$ & $\geq 3.19$ & $0.89 \pm 0.14$ & $0.35 \pm 0.05$ \\
\cline { 2 - 7 } & SiC Variant & $1.90 \pm 0.05$ & $\leq 1.03$ & $\geq 3.19$ & $2.39 \pm 0.24$ & $0.71 \pm 0.05$ \\
\hline
\end{tabular}

OPTAF $=(1+\mathrm{N}) /(1-\mathrm{N})$, where $\mathrm{N}$ is the measured optical diattenuation of the PyC.

The PyC density and SiC grain size are the critical metrics for defining acceptable $\mathrm{PyC} / \mathrm{SiC}$ diffusion couple specimens. Efforts are also underway to achieve a SiC density that meets the AGR-2 SiC density specification, however, the change in coating approach for the planar diffusion couple design relative to the coated particle efforts may not result in the appropriate density over the entire thickness of the SiC layer. The evidence for this is found in the initial results on the thick coating runs, which show an increase in porosity in the outer edge of the SiC layer that may influence the measured SiC density. These observations are shown later in Section 2.2. The PyC anisotropy will be measured. The unique geometry may limit the achievable anisotropy, as defined by the Optical Anisotropy Factor (OPTAF), in the planar 
diffusion couple design. Minor deviations from the PyC anisotropy specification may be tolerated, as diffusion in the $\mathrm{SiC}$ layer is the primary interest of this study.

A final criterion for the diffusion couple design is that it is an isolated system, which contains the introduced simulated fission products. The isolated system ensures that a fraction of the simulated fission products diffuse to the $\mathrm{SiC}$ layer through the $\mathrm{PyC}$ and are not lost to the surrounding system. This design essentially serves to mimic the interaction of fission products within the TRISO particle. The isolated system is also necessary as the high volatility of silver in particular would result in loss of the diffusing species to the surrounding environment. The loss of the diffusion species during thermal exposure would result in variable boundary conditions for diffusion analysis at different conditions.

\subsubsection{Fabrication Approach}

Multiple steps are involved in developing and fabricating the planer diffusion couple specimens. A visual representation of the general approach is shown in Figure 1 and can be summarized by the following steps: 1) build-up successive layers on a flat substrate, 2) introduce fission product species in PyC via ion implantation, 3) seal coat the diffusion couple with $\mathrm{SiC}$ to create an isolated system.

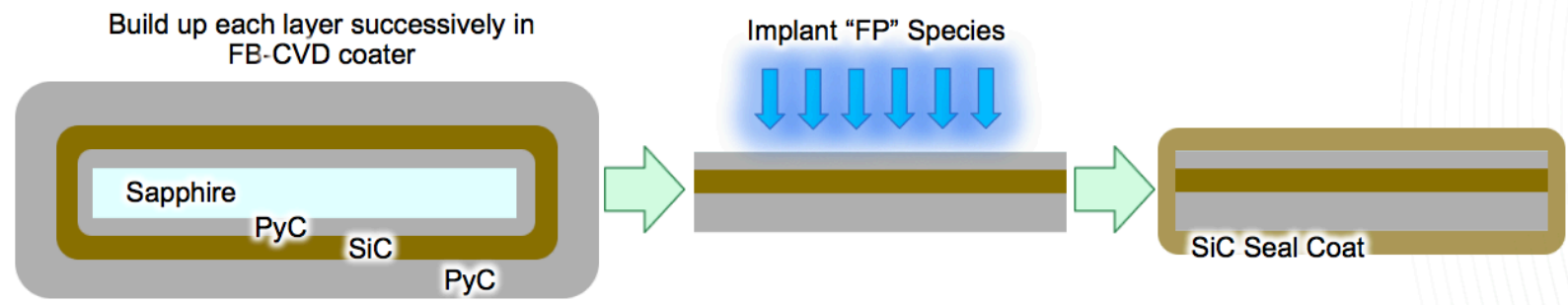

Figure 1. Schematic of diffusion couple fabrication process.

The $\mathrm{PyC} / \mathrm{SiC}$ interface and $\mathrm{SiC}$ microstructure are the primary features of interest for this study. A thin PyC layer was sought to ensure implanted fission product species interact with the SiC layer after thermal exposure. An initial target of 8-10 $\mu \mathrm{m}$ was defined. The upper bound on the effective diffusion length scale in $\mathrm{SiC}$ is on the order of 10-100 microns based on reported diffusion coefficients for the fastest diffusing species of $\mathrm{Ag}$ and most aggressive test conditions in Table 1 [8]. Based on this criterion a targeted $\mathrm{SiC}$ layer of $50 \mu \mathrm{m}$ was identified. Diffusion exposure times for the high temperature exposures can be modified to ensure measurable diffusion is less than the thickness of the SiC layer with appropriate properties. Following SiC deposition a thick support PyC layer was identified to be necessary to provide a robust substrate capable of being sectioned and handled. Pyrocarbon was selected for the support layer instead of $\mathrm{SiC}$ as the deposition rate of $\mathrm{PyC}$ is nearly one order of magnitude greater.

The following sections describe the research pathway to fabricate the planar TRISO diffusion couples.

\section{COATING EFFORTS}

A FBCVD process was used to fabricate the diffusion couple specimens. The coating process follows a modified procedure developed for the AGR program (AGR-Surrogate-Coat-SOP-01). Key differences here are substrate geometry, which is now approximately 9 -mm-diameter sapphire disks versus the previous surrogate (non-uranium) $400-\mu \mathrm{m}$-diameter $\mathrm{ZrO}_{2}$ particles, and the absence of the buffer layer. Details of the sapphire substrate selection can be found in Section 2.1. 
Even though the substrate of interest is now a sapphire disk, these disks (five per run) were still mixed with a large batch of the standard $400 \mu \mathrm{m} \mathrm{ZrO}_{2}$ particles to provide a fluidization medium. The disks make up a relatively small portion of the fluidized bed volume and have little impact on its behavior helping to make the coating layers deposited as representative as possible to the standard TRISO coatings.

Batch size for lab scale TRISO coating at ORNL is determined by surface area with a starting batch size of $1000 \mathrm{~cm}^{2}$ being typical. Surface area controls reactant flux at a given precursor concentration, which affects coating properties. Controlling batch surface area, rather than weight, minimizes coating property variations when particle size changes. The starting batch size for the $400 \mu \mathrm{m} \mathrm{ZrO}$ particles was increased since the typical $100 \mu \mathrm{m}$ buffer layer was omitted for this work and the IPyC layer thickness is reduced. This was done to attempt to match the surface area to that of a standard TRISO run at the start of the SiC deposition. This approximately $102 \mathrm{~g} \mathrm{ZrO}_{2}$ starting batch size was used for all the diffusion couple coating development runs except for the seal coating process, which is discussed in Section 4.

The FBCVD equipment at ORNL consists of a resistively-heated graphite furnace, which houses a conical graphite coating chamber. As shown in the schematic cutaway (Figure 2), the coating chamber is supported by a water-cooled gas injector allowing delivery of the coating precursor gases into the coating chamber. For a typical coating experiment, the $\mathrm{ZrO}_{2}$ particles and sapphire disks are loaded into the furnace at room temperature with argon gas flowing to maintain particle fluidization within the coating chamber. The furnace is brought to coating temperature and the individual layers are deposited by switching between each layer's respective precursor gasses. Table 3 shows examples of typical gas mixtures and temperatures used for the $\mathrm{PyC}$ and $\mathrm{SiC}$ layers. Once the coating experiment is complete, the furnace is brought back to room temperature and gas flow is shut off allowing the coated particles to drain through the injector and into the catch cup fixed to the bottom of the injector. The coated sapphire disks are too large to drain through the injector and require removal of the coating chamber from the furnace for extraction.

Table 3. Typical gas mixtures and temperatures used for $\mathrm{PyC}$ and $\mathrm{SiC}$ deposition.

\begin{tabular}{ccc}
\hline Coating layer & Gas Mixture & Temperature $\left({ }^{\circ} \mathbf{C}\right)$ \\
\hline $\mathrm{PyC}$ & $\mathrm{Ar}+\mathrm{C}_{2} \mathrm{H}_{2}+\mathrm{C}_{3} \mathrm{H}_{6}$ & $1250-1390$ \\
\hline $\mathrm{SiC}$ & $\mathrm{Ar}+\mathrm{H}_{2}+\mathrm{MTS}^{*}$ & $1425-1500$ \\
\hline
\end{tabular}

*MTS is methyltrichlorosilane $\left(\mathrm{CH}_{3} \mathrm{SiCl}_{3}\right)$ 
ORNL/TM-2017/704-R0

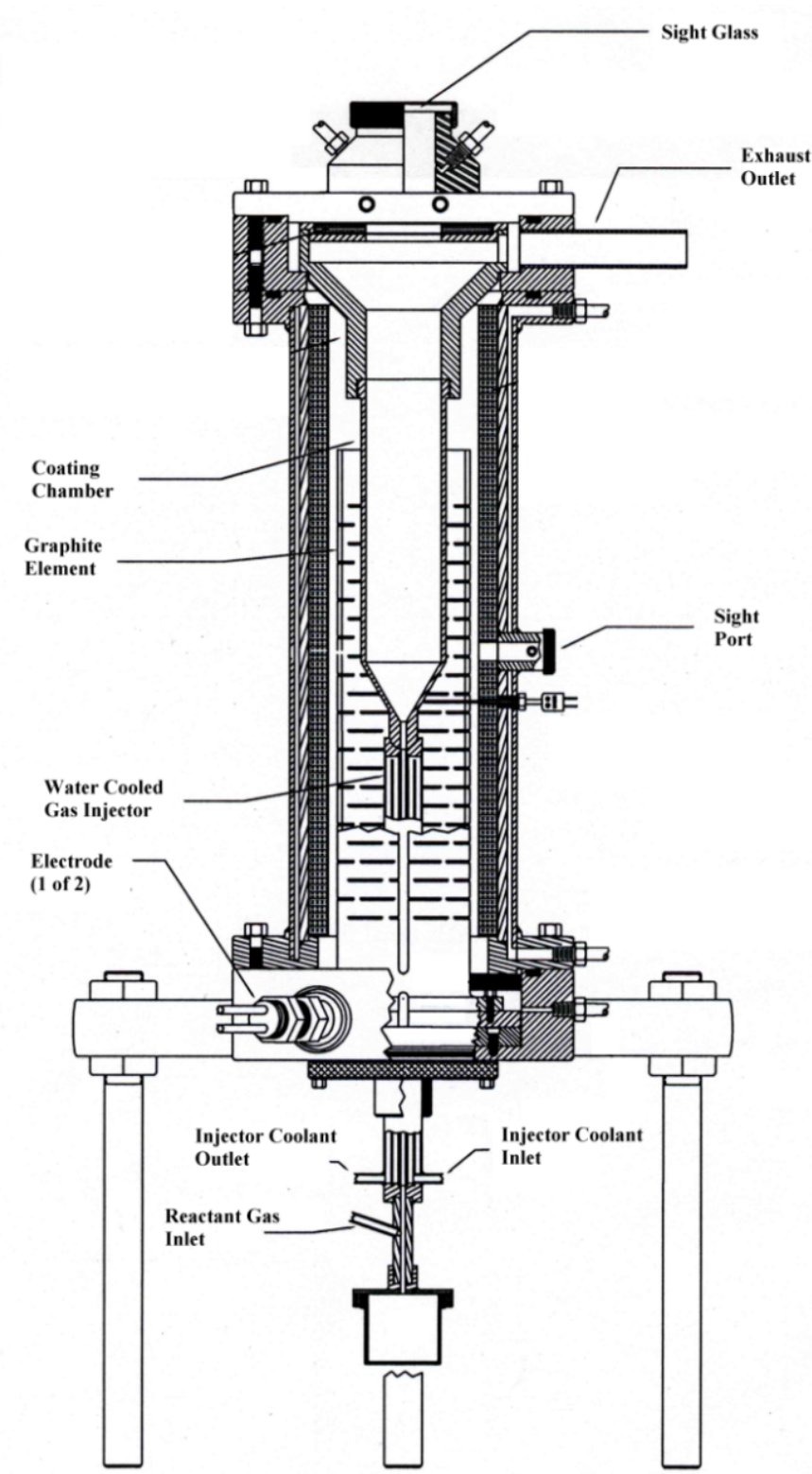

Figure 2. Schematic cutaway of the FBCVD equipment used for the diffusion couple coating development work.

\subsection{FLUIDIZATION CONFIRMATION}

Sapphire disk substrates were identified as ideal substrates to deposit the $\mathrm{PyC} / \mathrm{SiC} / \mathrm{PyC}$ layered structure because of the high temperature stability and variation in the coefficients of thermal expansion between the sapphire and PyC layers. This allows for the coated $\mathrm{PyC} / \mathrm{SiC} / \mathrm{PyC}$ layers to be easily removed from the sapphire substrate after deposition by sectioning the disks as the PyC layer does not adhere to the sapphire. The $\mathrm{PyC} / \mathrm{SiC} / \mathrm{PyC}$ layer must be removed to expose the PyC layer to allow for introduction of the fission product species by ion implantation and subsequent seal coating. The largest sapphire disk to be fluidized and which yields an even coating was sought. Targeting a large disk diameter has the benefit of increasing the number of samples yielded per coated disk as multiple samples could be extracted from 
each side. This also reduces the required number of coating runs. Initial coating runs attempted to fluidize various disk diameters with various thickness.

Commercially available sapphire disks from Meller Optics Inc. with diameters of approximately 3, 6, and $9 \mathrm{~mm}$ and thicknesses of 0.5 and $1 \mathrm{~mm}$ were investigated. Figure $3 \mathrm{a}$ shows the starting uncoated sapphire disk substrates and Figure $3 \mathrm{~b}$ shows a fully coated sapphire disk substrate. A total of five disks were fluidized simultaneously during initial $\mathrm{PyC}$ and $\mathrm{SiC}$ depositions along with approximately $102 \mathrm{~g}$ of 400 $\mu \mathrm{m} \mathrm{ZrO}_{2}$ particles. Details of $\mathrm{PyC} / \mathrm{SiC} / \mathrm{PyC}$ coating process are presented in 2.2.
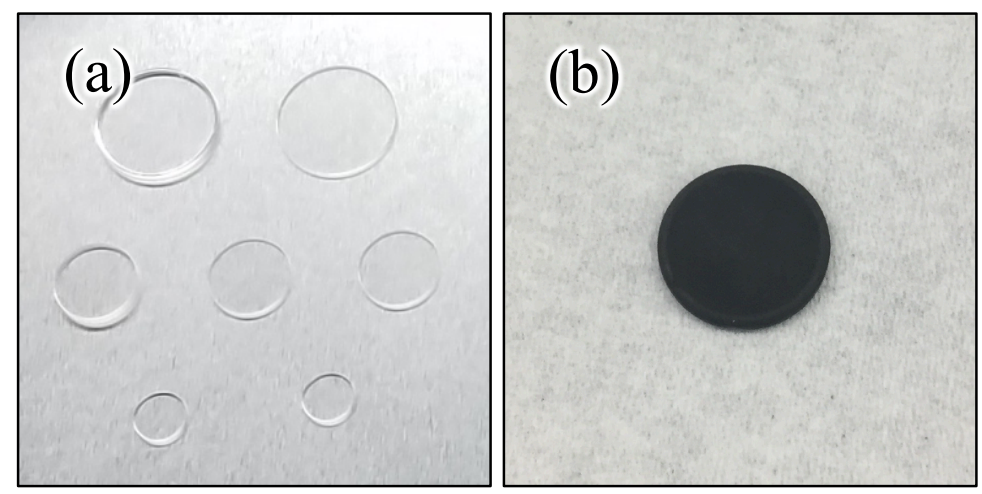

Figure 3. Image of (a) various uncoated sapphire dises and (b) $\mathrm{PyC} / \mathrm{SiC} / \mathrm{PyC}$ coated 9-mm-diameter, $0.5 \mathrm{~mm}$ thick sapphire disk.

Cross-sections of the edge of a thick, 9-mm-diameter PyC/SiC/PyC coated sapphire disc from the second full coating run (DCCD-02) are shown in Figure 4. The thickness of the coating layers is consistent across the majority of the disk surface, the exception being that a slight increase in thickness is observed in the immediate area of the disk edge. Chipping of the disk edges during the fluidization process was observed. Figure 5 shows an example of a chipped edge from a thick, 9-mm-diameter sapphire disk. The chip only influences the local layer structure, leaving the regions not associated with the chip intact and consistent. Chipping was not observed in all disks and chipping of the edges of thick disks $(1.0 \mathrm{~mm})$ was more frequently observed relative to the thin samples.

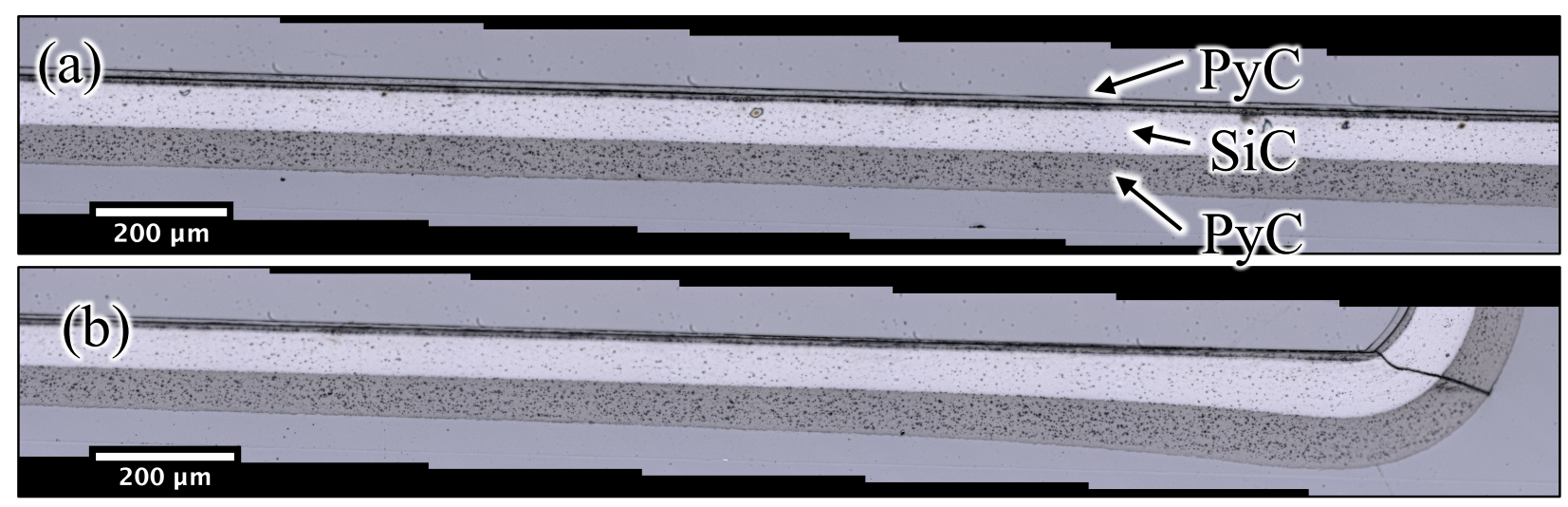

Figure 4. Optical micrographs of (a) center and (b) edge and adjacent area of a thick, 9-mm-diameter $\mathrm{PyC} / \mathrm{SiC} / \mathrm{PyC}$ coated sapphire disk (DCCD-02). 


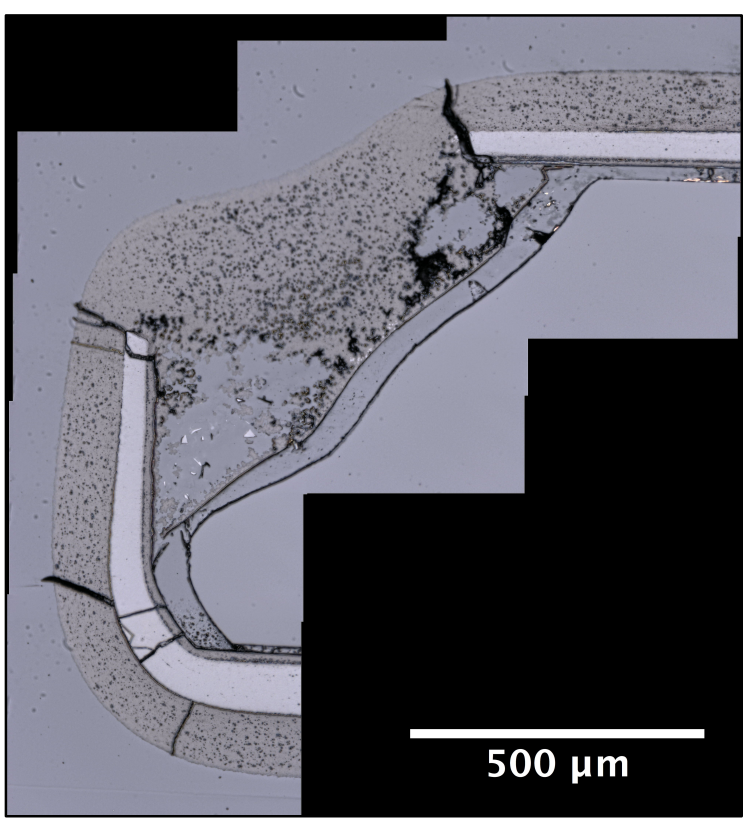

Figure 5. Example chipping of the coating and substrate during fluidization from a thick, 9-mm-diameter substrate (DCCD-02).

Fluidization of the 9-mm-diameter disks was considered ideal because of the large sample area with consistent layer thickness across the majority of the disk diameter. The higher frequency of chipping observed in the thick substrates pushed selection of the thin substrates. The final geometry of the diffusion couples sectioned from the $\mathrm{PyC} / \mathrm{SiC} / \mathrm{PyC}$ coated substrate were $3 \mathrm{~mm} \times 4 \mathrm{~mm}$ (length and width). Examples of the sectioned specimens are shown in Figure 6. This size allowed for avoidance of the edge effects. The size was also constrained by the capsule design (Section 5). Under this constraint and the use of the 9-mm-diameter substrate, four samples can be extracted from each disk, with a total of 20 samples per coating run assuming 100\% yield. This approach reduces the number of runs required to produce each test condition; improving potential issues associated with comparing across runs.

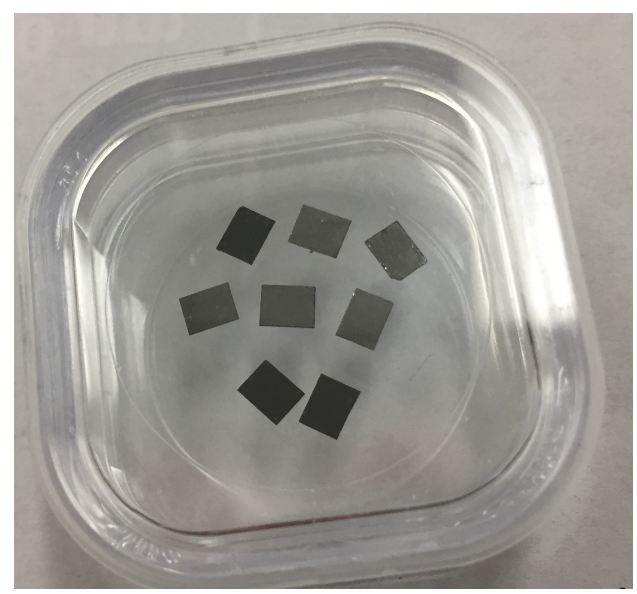

Figure 6. Sectioned PyC/SiC diffusion couple specimens from DCCD-03. 


\subsection{FULL COATING DEPOSITION}

Initial coating runs were conducted to determine general layer deposition conditions. This occurred alongside the selection of the ideal sapphire substrate.

As discussed earlier in Section 2, the sapphire disks were mixed with approximately $102 \mathrm{~g}$ of $\mathrm{ZrO}_{2}$ particles for all of the diffusion couple coating development runs. The 9-mm-diameter by 0.5 -mm-thick disks were used exclusively starting with run number DCCD-04. Processing conditions for each PyC, $\mathrm{SiC}$, and support PyC (S-PyC) layer for the coating development runs are shown in Table 4. The SiC layer for runs DCCD-02 through DCCD-06 was deposited using a 50/50 mixture of argon and hydrogen gas (in addition to the MTS) and is considered the Baseline material. By controlling the amount of MTS used, a consistent $\mathrm{SiC}$ layer thickness can be achieved between runs with $\mathrm{SiC}$ thickness of 51.6-54.9 $\mu \mathrm{m}$ for runs DCCD-03, DCCD-04, and DCCD-06. DCCD-17 was the first coating development run for the $\mathrm{SiC}$ variant. The primary differences between DCCD-17 and the previous runs was the use of pure hydrogen (rather than an $\mathrm{Ar} / \mathrm{H}_{2}$ blend) and a deposition temperature increase from $1425{ }^{\circ} \mathrm{C}$ to $1500{ }^{\circ} \mathrm{C}$. As discussed below, the $\mathrm{SiC}$ layer for DCCD-17 showed a high degree of porosity and a smaller grain size than expected, so further development work will be necessary to optimize the $\mathrm{SiC}$ variant processing conditions.

Table 4. Coating conditions of the $\mathrm{PyC} / \mathrm{SiC} / \mathrm{PyC}$ full coating depositions.

\begin{tabular}{|c|c|c|c|c|c|c|c|c|c|}
\hline Run & Layer & $\begin{array}{l}\text { Run } \\
\text { Time } \\
\text { (min) }\end{array}$ & $\begin{array}{c}\text { Temp. } \\
\left({ }^{\circ} \mathrm{C}\right)\end{array}$ & Ar & $\mathbf{H}_{2}$ & $\mathbf{C}_{2} \mathbf{H}_{2}$ & $\mathbf{C}_{3} \mathbf{H}_{6}$ & CGF & $\begin{array}{c}\text { MTS } \\
\text { used } \\
\text { (g) }\end{array}$ \\
\hline \multirow{3}{*}{ DCCD-02 } & $\mathrm{PyC}$ & 2.8 & 1295 & 6300 & - & 1460 & 1240 & 0.3 & - \\
\hline & $\mathrm{SiC}$ & 269 & 1425 & 3250 & 3250 & - & - & 0.015 & 180 \\
\hline & S-PyC & 46 & 1320 & 6300 & - & 1460 & 1240 & 0.3 & - \\
\hline \multirow{3}{*}{ DCCD-03 } & PyC & 2.8 & 1295 & 6300 & - & 1460 & 1240 & 0.3 & - \\
\hline & $\mathrm{SiC}$ & 250 & 1425 & 3250 & 3250 & - & - & 0.016 & 181 \\
\hline & S-PyC & 46 & 1320 & 6300 & - & 1460 & 1240 & 0.3 & - \\
\hline \multirow{3}{*}{ DCCD-04 } & $\mathrm{PyC}$ & 2.8 & 1295 & 6300 & - & 1460 & 1240 & 0.0 & - \\
\hline & $\mathrm{SiC}$ & 244 & 1425 & 3250 & 3250 & - & - & 0.017 & 182 \\
\hline & S-PyC & 46 & 1320 & 6300 & - & 1460 & 1240 & 0.3 & - \\
\hline \multirow{3}{*}{ DCCD-06 } & $\mathrm{PyC}$ & 3 & 1335 & 6300 & - & 1460 & 1240 & 0.3 & - \\
\hline & $\mathrm{SiC}$ & 177 & 1425 & 3250 & 3250 & - & - & 0.023 & 180 \\
\hline & S-PyC & 45 & 1320 & 6300 & - & 1460 & 1240 & 0.3 & - \\
\hline \multirow{3}{*}{ DCCD-17 } & $\mathrm{PyC}$ & 4.43 & 1340 & 4200 & - & 973 & 827 & 0.3 & - \\
\hline & $\mathrm{SiC}$ & 147 & 1500 & - & 7000 & - & - & 0.026 & 186 \\
\hline & S-PyC & 46 & 1320 & 6300 & - & 1460 & 1240 & 0.3 & - \\
\hline
\end{tabular}

Note: All gas flow rates are in sccm; CGF is coating gas fraction defined as precursor gas flow divided by total gas flow.

The layer properties of thickness and microstructure were investigated by optical and electron microscopy analysis. The PyC density for specific deposition conditions was determined through interrupted coating runs separate from the full coating depositions (see Section 2.3). Initial coating runs showed significant pull out or porosity in the regions beyond the first $10 \mu \mathrm{m}$ of the SiC layer (Figure 7) as well as at the $\mathrm{PyC} / \mathrm{SiC}$ interface. This is especially evident in the $\mathrm{S}-\mathrm{PyC}$, however, the S-PyC layer was not optimized for its physical properties. The porosity of the SiC layer was reduced in DCCD-06 relative to DCCD-04 (Figure 7) the improvement in porosity is attributed to the increase in coating gas fraction from approximately 0.015 to 0.026 . Note, that coating gas fraction (CGF) is defined as precursor gas flow divided by total gas flow which is equivalent to percent concentration of precursor gas, that is, a CGF of 
0.015 for $\mathrm{SiC}$ deposition would have an MTS concentration of $1.5 \%$. While the AGR specification for MTS concentration calls for $1.5 \pm 0.5 \%$, when using larger substrates (such as the sapphire disks) previous work has shown that increasing the MTS concentration can reduce porosity in the SiC layer. The exact mechanism for this porosity reduction isn't clear, but is attributed to the modification of the SiC nucleation and grain growth resulting from the higher precursor availability during deposition.

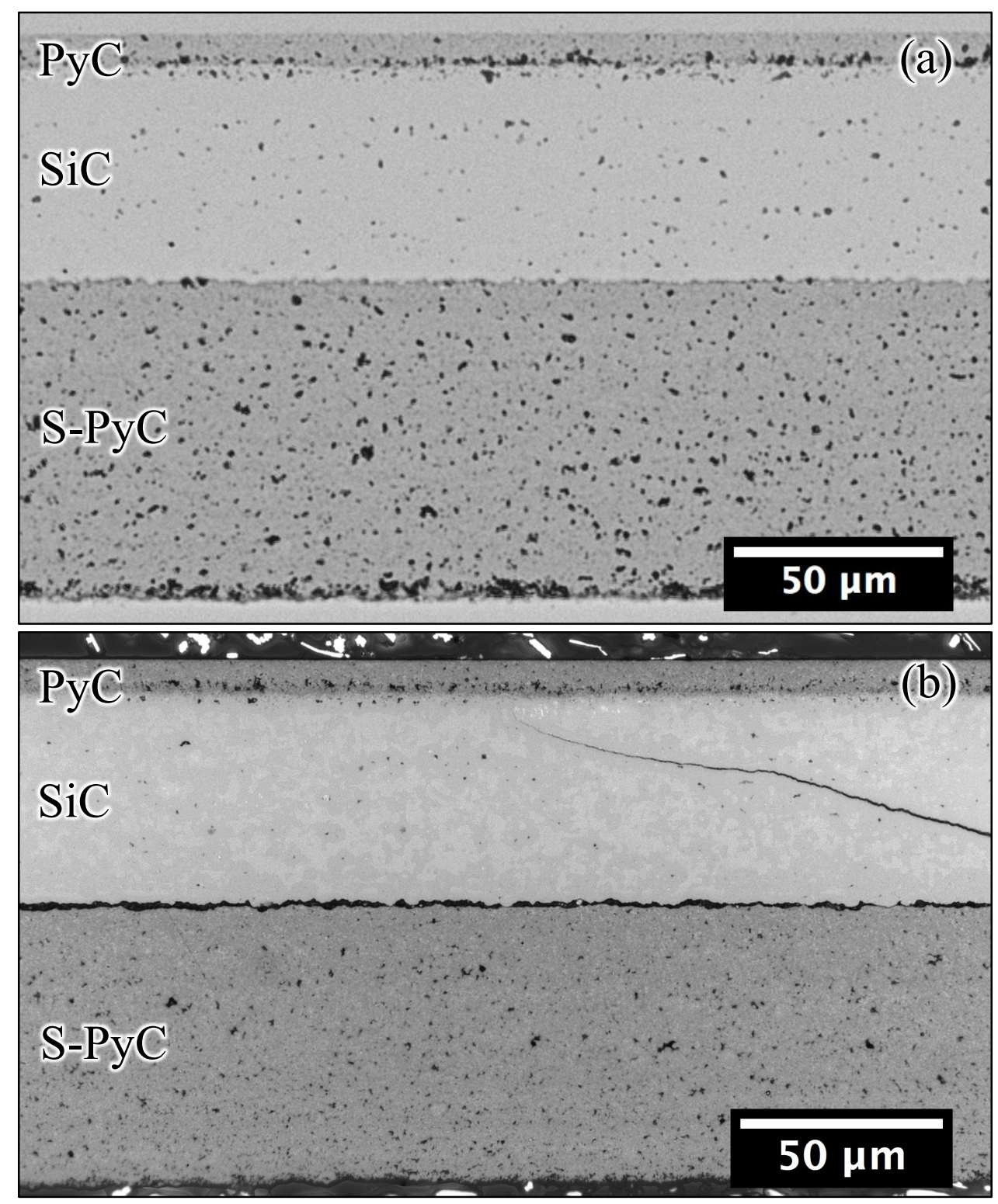

Figure 7. Optical image of the PyC/SiC/PyC layers of (a) DCCD-04 and (b) DCCD-06.

The SiC microstructure of DCCD-17 showed significant porosity (Figure 8 ). This coating run defines the starting conditions for which to begin improving the coating process to achieve the appropriate $\mathrm{SiC}$ variant microstructure. 


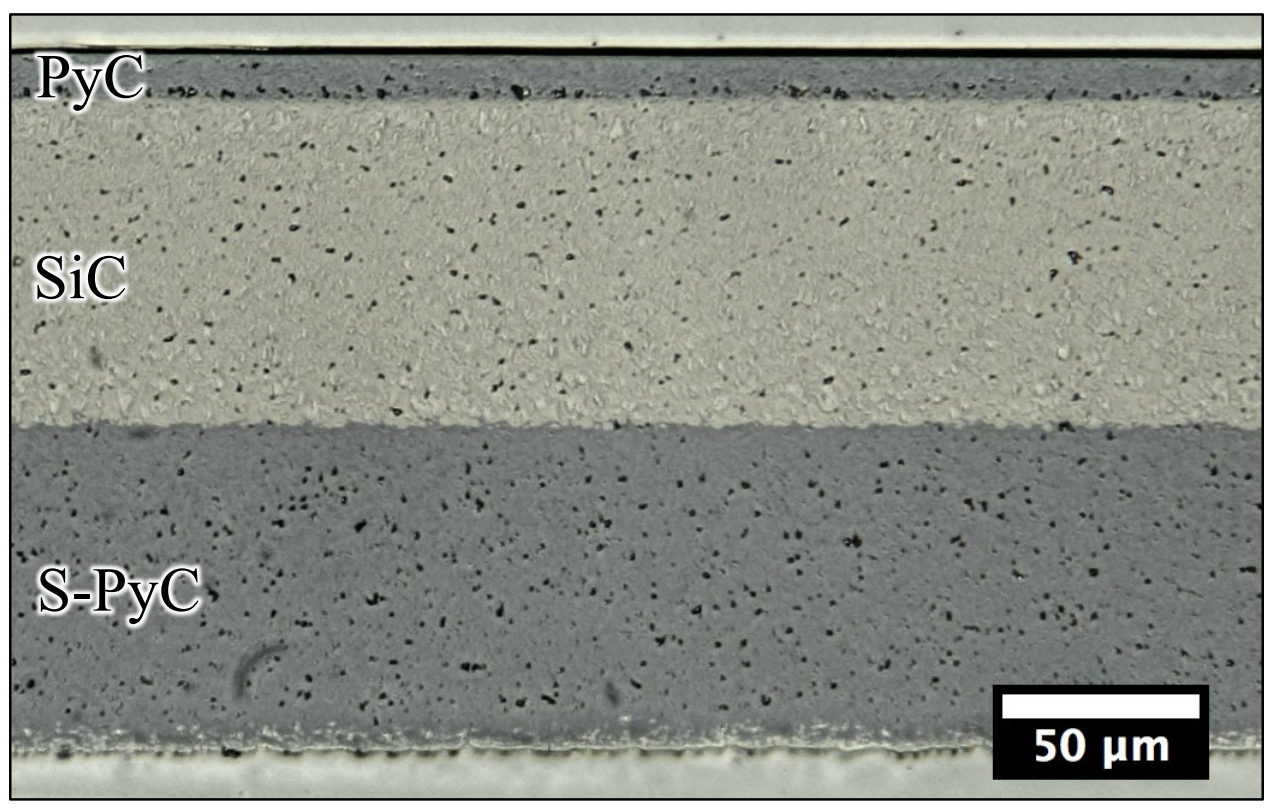

Figure 8. Optical micrograph of PyC/SiC/PyC layers from SiC variant DCCD-17.

Layer thicknesses were measured using the image processing software ImageJ. The results of the thickness measurements are shown in Table 5. Appropriate layer thicknesses were identified for the deposition of the PyC, SiC and S-PyC layers as 8-10 $\mu \mathrm{m}, 50-55 \mu \mathrm{m}$, and 70-75 $\mu \mathrm{m}$, respectively. The coating durations were selected to attempt to achieve thicknesses within these ranges based on expected deposition rates. Some variation in thickness is expected from the fluidization behavior and can be tolerated in the design. The baseline runs of DCCD-04 and DCCD-06 represent near ideal layer thicknesses. In DCCD-17 the SiC thickness is much greater than the expected thickness. This increased thickness is assumed to result from the porosity which likely produces a low-density SiC microstructure (Figure 8).

Table 5. Average layer thicknesses for full $\mathrm{PyC} / \mathrm{SiC} / \mathrm{PyC}$ coating runs.

\begin{tabular}{cccc}
\hline Sample & PyC Thickness $(\boldsymbol{\mu m})$ & SiC Thickness $(\boldsymbol{\mu m})$ & S-PyC Thickness $(\mu \mathrm{m})$ \\
\hline DCCD-02 & $11.7 \pm 0.3$ & $79.6 \pm 0.3$ & $71.7 \pm 0.9$ \\
\hline DCCD-03 & $8.6 \pm 0.1$ & $54.9 \pm 0.2$ & $84.3 \pm 0.7$ \\
\hline DCCD-04 & $7.4 \pm 0.3$ & $52.4 \pm 0.4$ & $75.3 \pm 0.6$ \\
\hline DCCD-06 & $8.3 \pm 0.1$ & $51.6 \pm 0.2$ & $68.4 \pm 0.4$ \\
\hline DCCD-17 & $9.5 \pm 0.3$ & $75.5 \pm 0.3$ & $70.8 \pm 0.3$ \\
\hline
\end{tabular}

The \pm values indicate one standard deviation in the distribution from the mean value.

The microstructure of the SiC layer was investigated by electron backscatter diffraction (EBSD). The EBSD analysis was conducted by following a similar approach to the method developed for measuring the $\mathrm{SiC}$ microstructure of AGR-1 and AGR-2 TRISO particles [23]. Data was acquired using an FEI Versa3D DualBeam FIB-SEM equipped with a Schottky field emission source, and an Oxford Instruments HKL Nordlys EBSD system located in the Low Activation Materials Development and Analysis laboratory at ORNL. The acquired data was imported into EDAX OIM v7 software for data analysis. Data was acquired using a $30 \mathrm{kV}, 11 \mathrm{nA}$ beam and a $0.05-0.1 \mu \mathrm{m}$ step size. A minimum of 5 degrees misorientation was required to define a unique grain for grain size statistics. The area adjacent to the $\mathrm{PyC} / \mathrm{SiC}$ interface was analyzed as it represents the area subjected to diffusion analysis. Grain size is 
reported in major and minor axis in lieu of grain diameter as the FBCVD process results in a non-equiaxed microstructure. Representation of the grain size as major and minor axis is also relevant for comparison with the measured $\mathrm{SiC}$ layer grain size from AGR-1 and AGR-2. EBSD has been performed on coating runs DCCD-03, DCCD-06, and DCCD-17.

An example of an acquired EBSD map is shown in Figure 9. Here an image quality (IQ) map is presented along with an inverse pole figure (IPF) map. The IQ map shows the quality of the acquired pattern associated with each point while the IPF map shows the relative orientation of each point in the scan. From Figure 9 the expected elongated grain structure is observed, with the major axis near parallel to the growth direction.

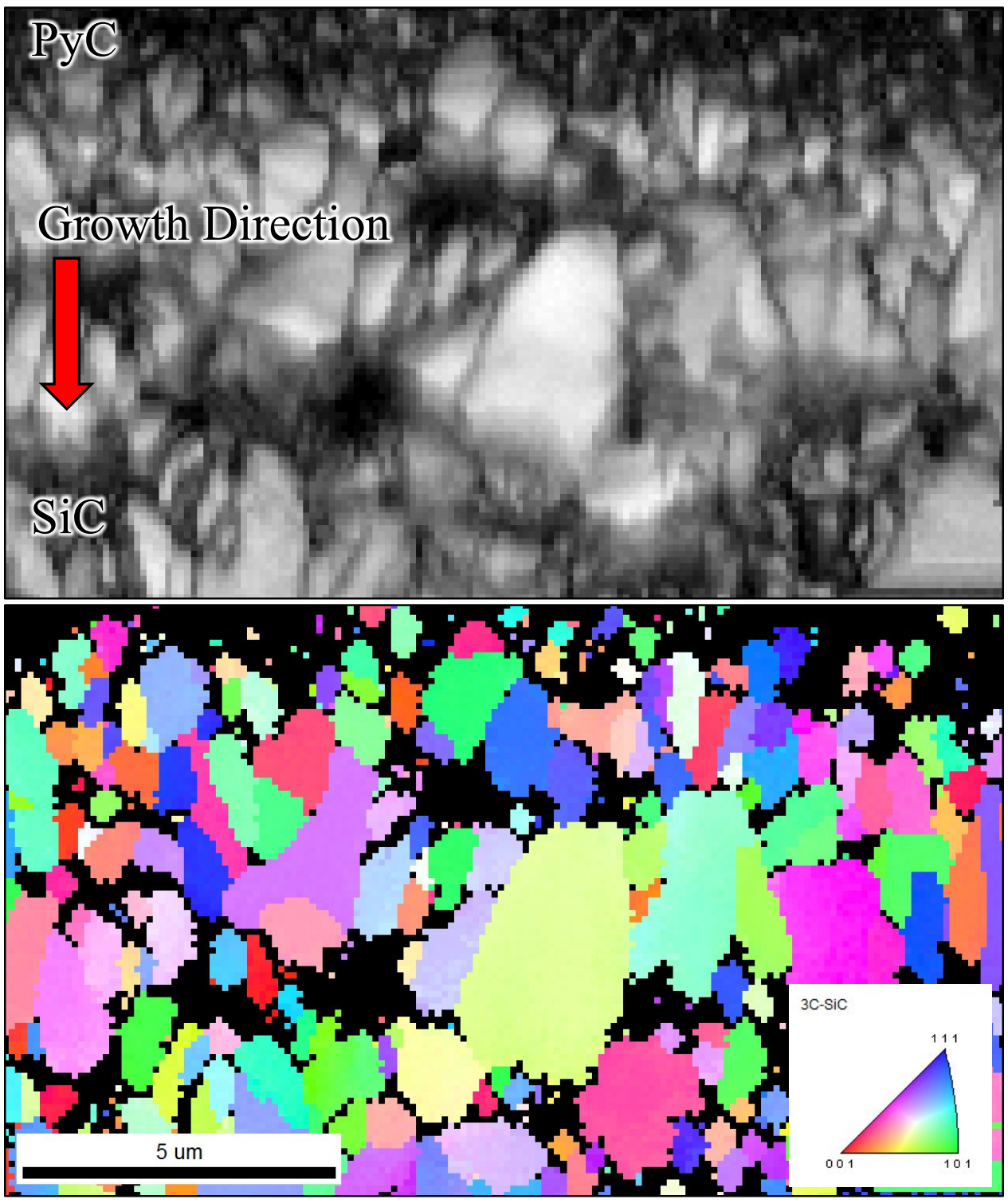

Figure 9. EBSD analysis of DCCD-17 showing IQ and IPF maps of SiC layer adjacent to PyC.

The grain size for the three samples analyzed by EBSD are presented in Table 6 . The grain size for the two Baseline variants bounded the targeted major and minor axes $(0.89 \mu \mathrm{m}$ and $0.35 \mu \mathrm{m}$ respectively). This, along with the limited porosity observed in DCCD-06, suggests the deposition parameters of 
DCCD-06 were close to satisfying the requirements of the Baseline variant. A slightly larger grain size will be targeted in subsequent runs by exploring the impact of deposition temperature while keeping the other deposition conditions constant relative to DCCD-06. However, because a visual specification is used to define the AGR-2 SiC microstructure, no tolerance for acceptable deviation from the measured grain size has been defined. The $\mathrm{SiC}$ variant microstructure is not similar to the targeted $\mathrm{SiC}$ grain size. A depth dependence on grain size was noted for the pure hydrogen SiC deposition in TRISO fuel, with the initial $\mathrm{PyC} / \mathrm{SiC}$ interface possessing a smaller relative grain size to the remainder of the $\mathrm{SiC}$ [23, 24]. However, this depth dependence is not expected to be responsible for the small grains size, as the initial grains close to the $\mathrm{PyC} / \mathrm{SiC}$ interface are similar in size to the grains further from the interface. Deposition temperature and CGF will be adjusted to control grain size and porosity for the $\mathrm{SiC}$ variant deposition to achieve a SiC layer with the targeted properties. Note, density measurements will be performed on $\mathrm{SiC}$ layers which exhibit the appropriate microstructure for the targeted variant

Table 6. EBSD grain size measurements.

\begin{tabular}{cccc}
\hline Run & Variant & Major Axis $(\boldsymbol{\mu m})$ & Minor Axis $(\boldsymbol{\mu m})$ \\
\hline DCCD-03 & Baseline & $1.05 \pm 0.26$ & $0.41 \pm 0.09$ \\
\hline DCCD-06 & Baseline & $0.67 \pm 0.13$ & $0.25 \pm 0.04$ \\
\hline DCCD-17 & $\mathrm{SiC}$ & $0.82 \pm 0.24$ & $0.38 \pm 0.13$ \\
\hline
\end{tabular}

The \pm values indicate one standard deviation in the distribution from the mean value.

\subsection{PYC LAYER PROPERTIES}

A systematic approach was undertaken to obtain the ideal PyC layer properties in the $\mathrm{PyC} / \mathrm{SiC}$ diffusion couples. Interrupted PyC-only coatings were produced to allow for direct density measurement through the use of a density column following the procedure AGR-CHAR-DAM-03 Rev. 4 developed for the AGR program. Density is considered the primary metric for comparing to AGR TRISO fuel. Anisotropy measurements are also being developed to compare to AGR TRISO fuel, but will only be made on completed diffusion couples because of thickness and polishing issues.

The coating conditions for the first series of interrupted runs are shown in Table 7. These PyC only runs are denoted as DCCD-\#\#I and were performed using the same procedure and $\mathrm{ZrO}_{2} /$ sapphire substrate size as the baseline runs. Early in the PyC coating development process, the total gas flow was reduced from $9000 \mathrm{sccm}$ to $6000 \mathrm{sccm}$ as the particles were over-fluidized at the higher gas flows with some particles reaching the top of the coating chamber near the furnace exhaust. After run DCCD-05I, gas flows were held constant, and temperature was used to vary the $\mathrm{PyC}$ density. As temperature also affects coating rate, run time was varied accordingly to maintain similar layer thicknesses between each of the PyC only runs.

Table 7. Coating conditions of the first series of PyC only interrupted runs.

\begin{tabular}{|c|c|c|c|c|c|c|c|}
\hline Run & $\begin{array}{l}\text { Run } \\
\text { Time }\end{array}$ & Temperature & $\begin{array}{c}\text { Ar } \\
\text { Fluid. } \\
\text { Gas }\end{array}$ & $\mathrm{C}_{2} \mathrm{H}_{2}$ & $\mathbf{C}_{3} \mathbf{H}_{6}$ & CGF* & $\begin{array}{c}\text { PyC Density } \\
\left(\mathrm{g} / \mathrm{cm}^{3}\right)\end{array}$ \\
\hline DCCD-05I & $4.6 \mathrm{~min}$ & $1295^{\circ} \mathrm{C}$ & 6300 & 1460 & 1240 & 0.30 & $1.984 \pm 0.002$ \\
\hline DCCD-07I & $4.5 \mathrm{~min}$ & $1335^{\circ} \mathrm{C}$ & 4200 & 973 & 827 & 0.30 & $1.837 \pm 0.018$ \\
\hline DCCD-08I & $3.9 \mathrm{~min}$ & $1295^{\circ} \mathrm{C}$ & 4200 & 973 & 827 & 0.30 & $1.968 \pm 0.020$ \\
\hline
\end{tabular}




\begin{tabular}{cccccccc}
\hline DCCD -09I & $3.9 \mathrm{~min}$ & $1375{ }^{\circ} \mathrm{C}$ & 4200 & 973 & 827 & 0.30 & $1.727 \pm 0.004$ \\
\hline DCCD -10I & $5.8 \mathrm{~min}$ & $1255^{\circ} \mathrm{C}$ & 4200 & 973 & 827 & 0.30 & $2.008 \pm 0.008$ \\
\hline DCCD -11I & $5.8 \mathrm{~min}$ & $1295^{\circ} \mathrm{C}$ & 4200 & 973 & 827 & 0.30 & $1.976 \pm 0.008$
\end{tabular}

All gas flow rates are in sccm; *CGF is coating gas fraction defined as precursor gas flow divided by total gas flow; the \pm values indicate one standard deviation in the distribution from the mean value.

The dependence of PyC density on coating temperature for the first series of interrupted PyC coating runs are shown in Figure 10. The PyC density appeared to follow a linear dependence with temperature.

Variation in coating gas flow and fraction did not have a strong influence on the resulting PyC density as noted from the similar results from DCCD-05I, DCCD-08I, and DCCD-11I. Based on the linear dependence a coating temperature of $1310^{\circ} \mathrm{C}$ was identified as the appropriate condition to obtain a PyC density of $\sim 1.90 \mathrm{~g} / \mathrm{cm}^{3}$ per the targeted value.

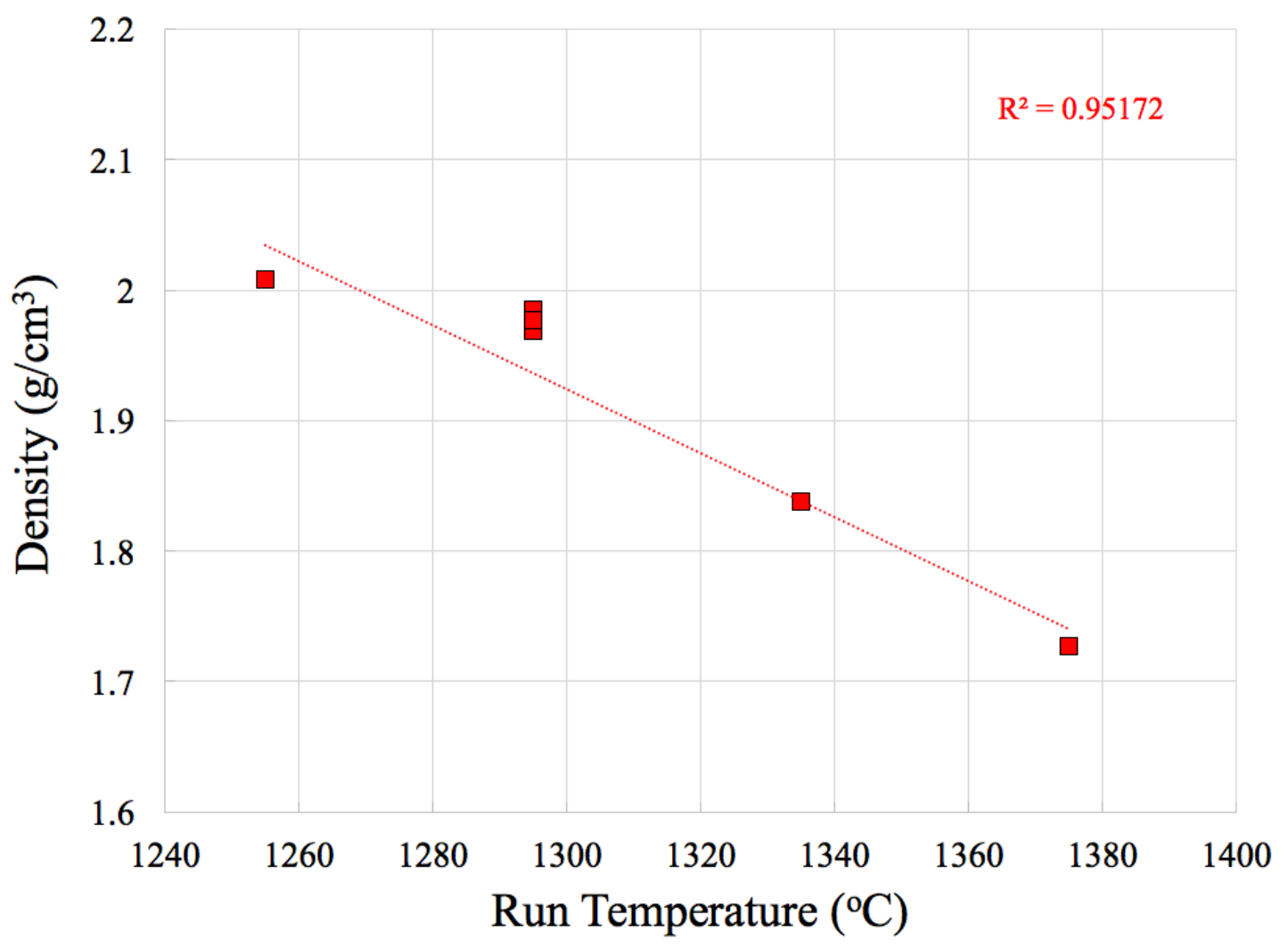

Figure 10. PyC density as a function of coating temperature for first series of interrupted coatings, the linear fit is shown as a dashed line.

After the DCCD-11I coating run the furnace element was replaced as the graphite element was oxidized which rendered the furnace inoperable. The oxidized graphite furnace element and new graphite element are shown in Figure 11. Following the exchange of the furnace elements the $1310^{\circ} \mathrm{C}$ run was completed (DCCD-12I) and produced density of $1.989 \pm 0.281 \mathrm{~g} / \mathrm{cm}^{3}$. The elevated uncertainty in DCCD-12I prompted a second coating at $1310^{\circ} \mathrm{C}$ which resulted in a measured density of $1.973 \pm 0.069 \mathrm{~g} / \mathrm{cm}^{3}$. Both of these measurements were outside of the Baseline PyC density specification which was intended to be 
achieved based on the linear dependence observed in the first PyC coating series. The calibration and readouts for furnace gas flow systems were checked to ensure no issues were present. The gas delivery system displayed no issues as such the variation in coating performance was assumed to be solely resultant from changes in the thermal profile in the system with a pristine element.

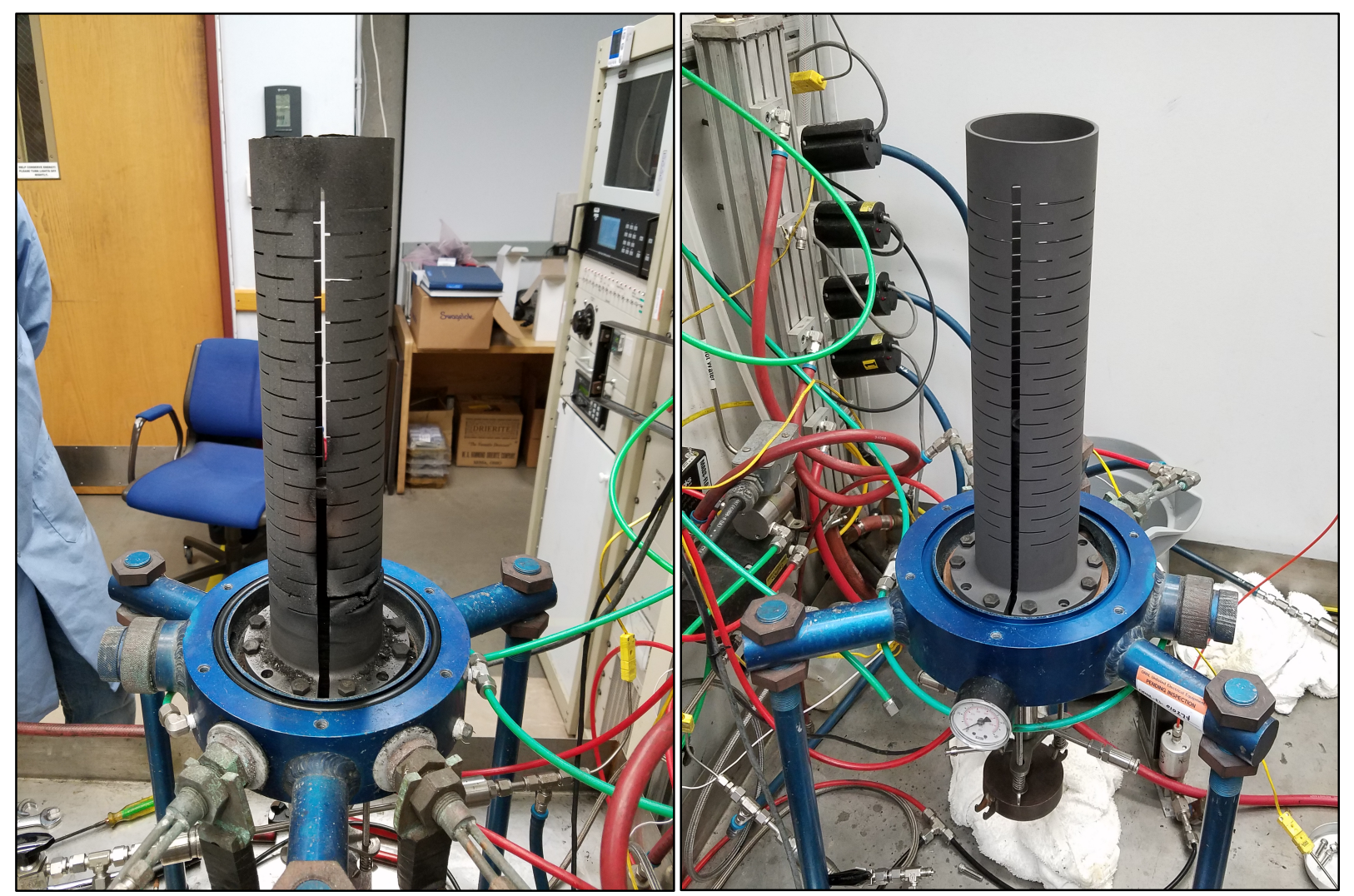

Figure 11. Oxidized graphite furnace element and replacement element for fluidized bed-coater.

A second PyC coating series was conducted to determine the temperature dependence on the PyC density with the new furnace element. Table 8 shows the coating conditions for the second series. The density dependence on temperature results from the second series are shown along with the results for the first series in Figure 12. The results from the second series indicated that there is a $10-20{ }^{\circ} \mathrm{C}$ shift to higher temperature for the second series. The results from the second series also show a deviation from a linear dependence of PyC density on temperature where a second order polynomial showed the best empirical fit of the data. Note, the data for DCCD-15I is underestimated because a number of PyC fragments were not able to be measured as they were out of range of the calibration floats used in the density column. The upper bound estimate of the density of DCCD-15I is approximately $2.05 \mathrm{~g} / \mathrm{cm}^{3}$. The impact of the underestimated density of DCCD-15I has limited impact on the polynomial fit in the temperature range expected to produce the Baseline PyC conditions as indicated in Figure 12. 
Table 8. Coating conditions of the second series of PyC only interrupted runs.

\begin{tabular}{cccccccc}
\hline Run & $\begin{array}{c}\text { Run } \\
\text { Time }\end{array}$ & Temperature & $\begin{array}{c}\text { Ar } \\
\text { Fluid. } \\
\text { Gas }\end{array}$ & $\mathbf{C}_{2} \mathbf{H}_{2}$ & $\mathbf{C}_{3} \mathbf{H}_{6}$ & $\mathbf{C G F}^{*}$ & $\begin{array}{c}\text { PyC Density } \\
\left(\mathbf{g} / \mathbf{c m}^{\mathbf{3}} \mathbf{)}\right.\end{array}$ \\
\hline DCCD-12I & $4.9 \mathrm{~min}$ & $1310^{\circ} \mathrm{C}$ & 4200 & 973 & 827 & 0.30 & $1.989 \pm 0.281$ \\
\hline DCCD-13I & $4.9 \mathrm{~min}$ & $1310^{\circ} \mathrm{C}$ & 4200 & 973 & 827 & 0.30 & $1.973 \pm 0.069$ \\
\hline DCCD-14I & $4.3 \mathrm{~min}$ & $1350{ }^{\circ} \mathrm{C}$ & 4200 & 973 & 827 & 0.30 & $1.883 \pm 0.026$ \\
\hline DCCD-15I & $5.5 \mathrm{~min}$ & $1270{ }^{\circ} \mathrm{C}$ & 4200 & 973 & 827 & 0.30 & $2.011 \pm 0.002^{\wedge}$ \\
\hline DCCD-16I & $6.6 \mathrm{~min}$ & $1390{ }^{\circ} \mathrm{C}$ & 4200 & 973 & 827 & 0.30 & $1.754 \pm 0.038$ \\
\hline DCCD-18I & $4.5 \mathrm{~min}$ & $1340{ }^{\circ} \mathrm{C}$ & 4200 & 973 & 827 & 0.30 & $1.946 \pm 0.015$ \\
\hline
\end{tabular}

All gas flow rates are in sccm; *CGF is coating gas fraction defined as precursor gas flow divided by total gas flow; the \pm values indicate one standard deviation in the distribution from the mean value.

${ }^{\wedge}$ The density for DCCD-15I is underestimated.

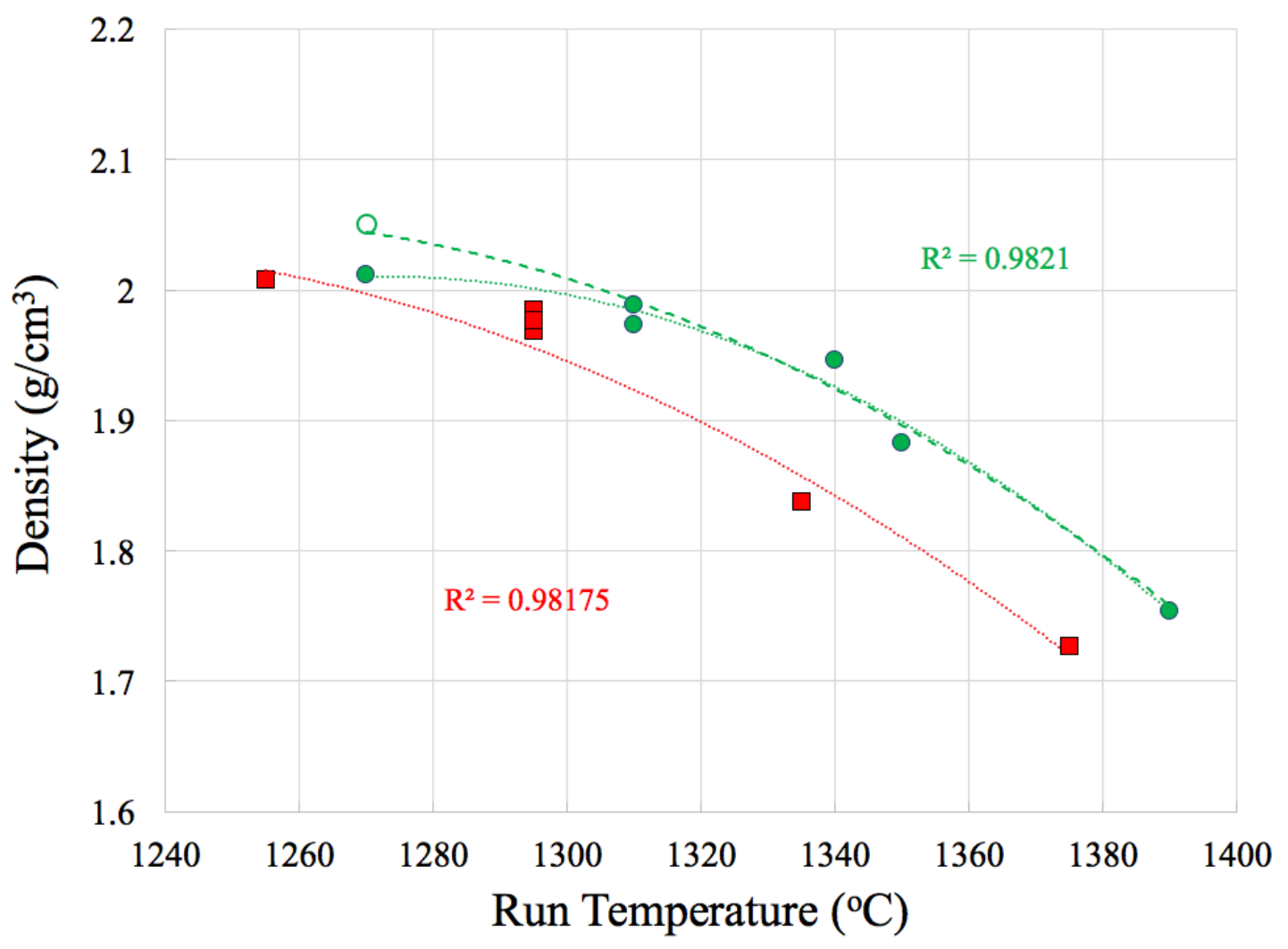

Figure 12. PyC density as a function of coating temperature for first (red squares) and second (green circles) series of interrupted PyC coatings the polynomial fits are shown as dotted lines. The estimated upper bound of DCCD-15I is shown as an unfilled green circle with the polynomial fit as a dashed green line. 
Run DCCD-14I resulted in a PyC density that would satisfy the Baseline specification. This is supported by the polynomial fit, which indicates the run temperature of $1350{ }^{\circ} \mathrm{C}$ (DCCD-14I) should result in the targeted PyC density of approximately $1.90 \mathrm{~g} / \mathrm{cm}^{3}$. A repeat of the DCCD-14I run condition $\left(1350{ }^{\circ} \mathrm{C}\right)$ and a lower temperature run $\left(1340{ }^{\circ} \mathrm{C}\right)$ have been completed to confirm the results. Density measurements are in progress to confirm the ideal $\mathrm{PyC}$ run conditions for both Baseline and the SiC variant. From the polynomial fit a lower temperature run below $1320{ }^{\circ} \mathrm{C}$ will result in a $\mathrm{PyC}$ density $>1.95 \mathrm{~g} / \mathrm{cm}^{3}$ which would satisfy the PyC variant requirement. However, based on the range of achievable PyC densities, a PyC density near $2.0 \mathrm{~g} / \mathrm{cm}^{3}$ will be produced for the PyC variant by depositing at a temperature of $\sim 1300{ }^{\circ} \mathrm{C}$. The motivation for the higher density PyC layer is that it ensures that a distinct difference in interfacial structure between the Baseline and $\mathrm{PyC}$ variants is explored.

\subsubsection{Supplemental PyC Analysis}

\subsubsection{Anisotropy}

The Two-Modulator Generalized Ellipsometry Microscope (2-MGEM) was used to measure anisotropy on the thin PyC layer. The lateral resolution of the system is approximately $5 \mu \mathrm{m}$. This lateral resolution combined with the thickness of the PyC layer results in only one to two data points across the PyC layer in cross-section. The PyC/SiC/S-PyC layers were polished at a slight angle to increase the surface area of the thin PyC layer. This provides opportunity to collect multiple data points in the layer from across the entire thickness of the PyC layer. Figure 13 shows a comparison of the inclined polished sample and a $90^{\circ}$ cross-sectioned sample from DCCD-06. The end result was an increase in polished thickness of approximately 7 times the original thickness. 


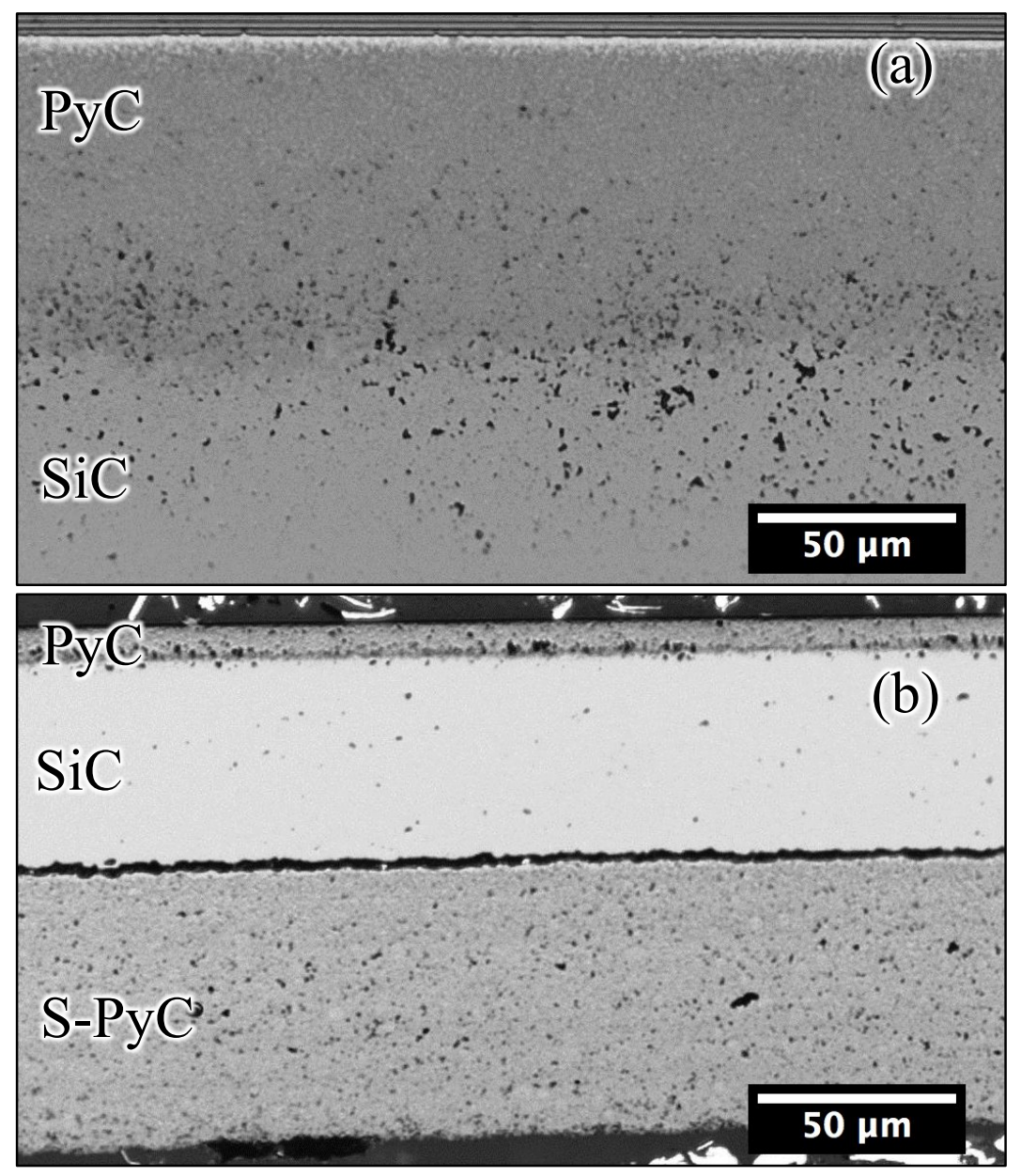

Figure 13. Optical images of (a) and inclined polished sample and (b) cross-section polished sample.

The 2-MGEM analysis is shown in Figure 14. The general observation is that the intensity of the reflected light in the PyC layer was too low to get quality measurements in the PyC region of interest. The initial measurements produced an average diattenuation value of $0.0040 \pm 0.0021$ (the \pm values indicate one standard deviation). The large standard deviation is an indicator of the low confidence in the analysis. The measured diattenuation equates to an OPTAF of $1.008 \pm 0.003$ (the \pm values indicate one standard deviation). This value is outside of the range of targeted properties for the PyC layer. As noted, the intensity limits the confidence in the results and improvement of the approach is necessary. It is likely that the softness of the epoxy used to prepare the sample led to rounding of the PyC layer during sample polishing. The non-flat nature of the sample would limit the light reflected back from the surface. To improve upon the measurements new polishing procedures can be adopted which provides an appropriately flat sample. Improvement in sample preparation will include investigating fully $\mathrm{PyC} / \mathrm{SiC} / \mathrm{PyC}$ samples with a $\mathrm{SiC}$ seal coat. The $\mathrm{SiC}$ seal coat will provide structural integrity to limit rounding. A change to the polishing procedure will also be implanted to ensure a flat surface is maintained. 

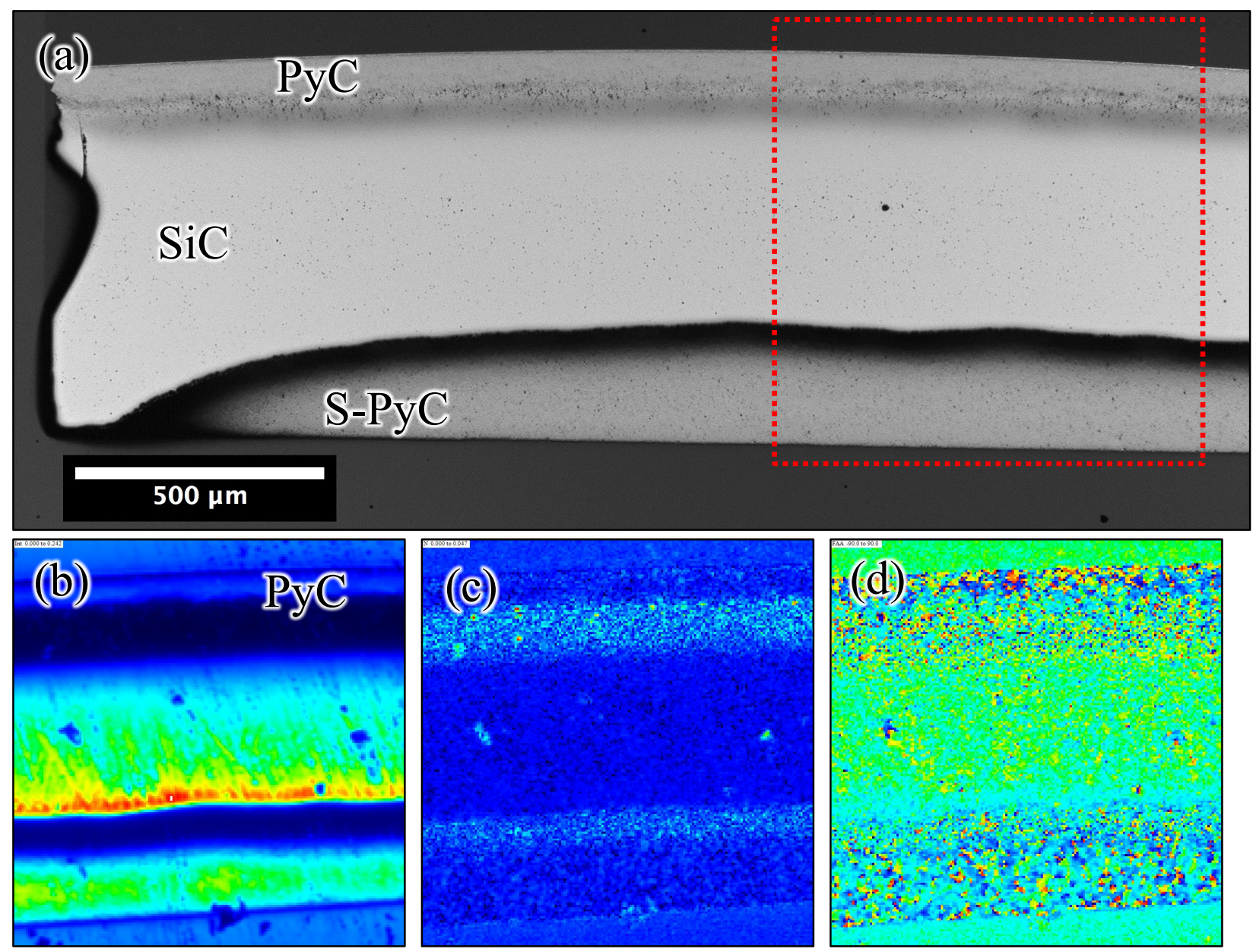

Figure 14. Analysis of inclined polished sample showing (a) an overview optical image with location of 2-MGEM scan, (b) intensity map, (c) diattenuation map, and (d) fast axis angle map.

\subsubsection{3D Imaging of PyC/SiC Interface}

The nature of the $\mathrm{PyC} / \mathrm{SiC}$ interface is important concerning the behavior of fission products with the $\mathrm{SiC}$ layer in TRISO fuel. In particular the $\mathrm{SiC}$ features, which extend into the open volume of the PyC layer after deposition are observed to interact with fission product species [25]. This interfacial SiC may serve to immobilize select fission products or influence uptake into the $\mathrm{SiC}$ layer. To better define the $\mathrm{PyC} / \mathrm{SiC}$ interface FIB-SEM tomography was performed using an FEI Versa3D DualBeam FIB-SEM with Auto Slice and View. This allowed for submicron resolution three-dimensional reconstructions of the $\mathrm{PyC} / \mathrm{SiC}$ interface to be generated. Figure 15 shows the three-dimensional representation of each interfacial component from sample DCCD-06 and represents a demonstration of the capability. A qualitative assessment of the reconstructed volume shows the interfacial stitching extends approximately $8-10 \mu \mathrm{m}$ into the $\mathrm{SiC}$ layer. This interfacial layer also shows measurable open volume associated with pores at the $\mathrm{PyC} / \mathrm{SiC}$ interface. 

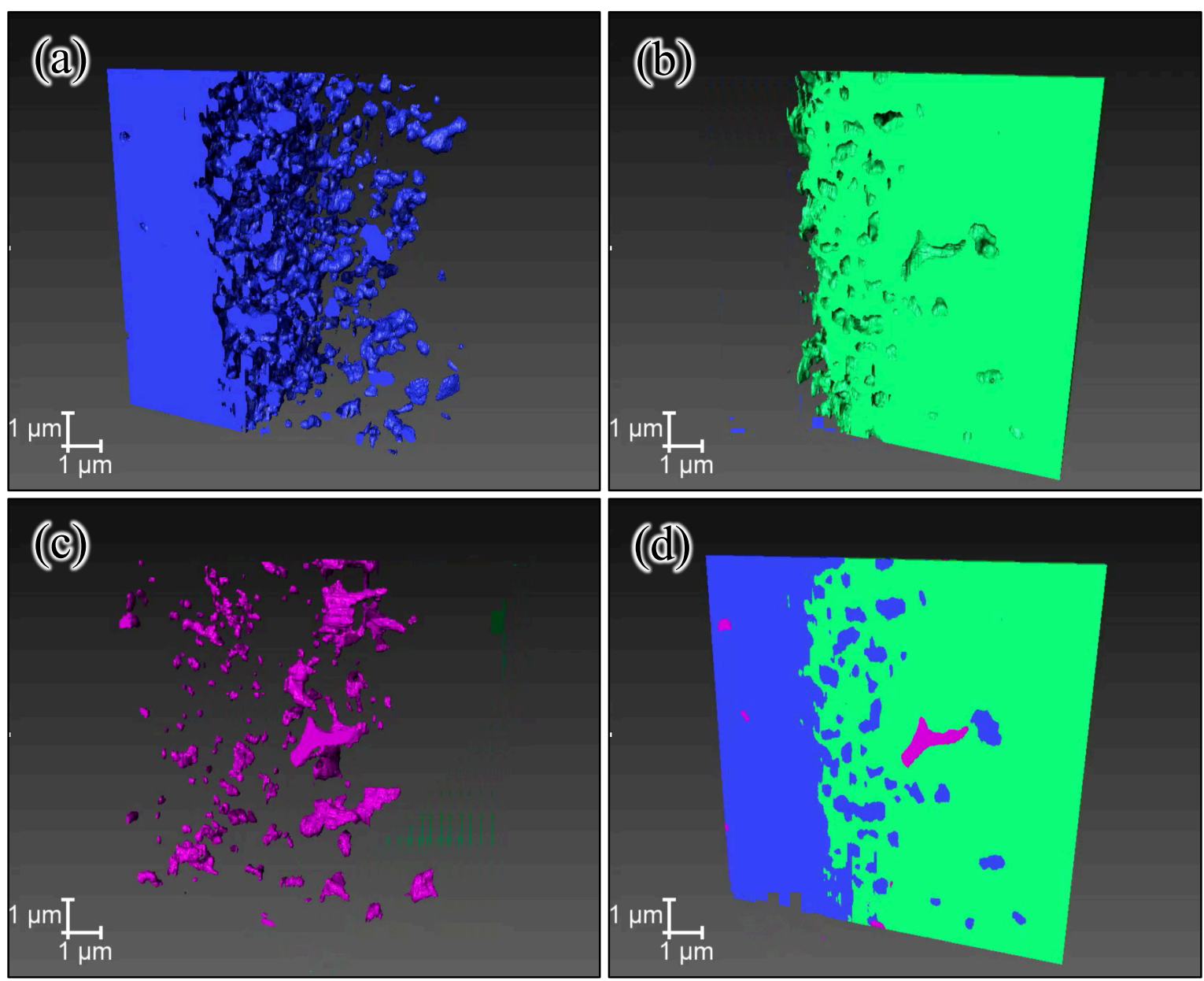

Figure 15. 3D representations of different components of the $\mathrm{PyC} / \mathrm{SiC}$ interface from DCCD-04; (a) PyC, (b) $\mathrm{SiC}$, and (c) open volume, with the reconstructed volume shown in (d).

The analysis is preliminary and on a non-optimized sample, however, it shows the complex nature of the $\mathrm{PyC} / \mathrm{SiC}$ interface. The data will be further analyzed to determine the total surface area of the individual components, total open volume, and compositional variation as a function of depth. The successes of this first approach suggest future three-dimensional tomography analysis of the diffusion couples (irradiated and unirradiated) could provide unique insight on the impact of the interfacial properties on interfacial reactions which occur between fission product species and the $\mathrm{SiC}$ layer at the $\mathrm{PyC} / \mathrm{SiC}$ interface.

\section{ION IMPLANTATION}

Ion implantation is being used to introduce the diffusion species to the $\mathrm{PyC} / \mathrm{SiC}$ diffusion couple specimens. The goal is to introduce an equivalent amount of the diffusing species into the PyC that would be expected to be present in a single TRISO particle at the end-of-life. To estimate this value, the amount of each fission product of interest and their isotopes (silver, palladium, europium, and strontium) were calculated from the burnup calculations by Sterbentz for AGR-2 [26]. A scaling factor was used to account for the change in geometry and volume from the spherical TRISO particle to the planar PyC/SiC diffusion couple specimen. 
Table 9. Planned dose for each sample condition.

\begin{tabular}{cccc}
\hline Condition & Energy (kV) & Fluence $\left(\mathbf{i o n} / \mathbf{c m}^{2}\right)$ & Temperature \\
\hline $\mathrm{Ag}$ & 400 & $4.20 \times 10^{16}$ & $25^{\circ} \mathrm{C}$ \\
\hline $\mathrm{Ag}+\mathrm{Pd}$ & 400 & $(\mathrm{Ag}) 4.20 \times 10^{16}(\mathrm{Pd}) 7.76 \times 10^{17}$ & $25^{\circ} \mathrm{C}$ \\
\hline $\mathrm{Eu}$ & 400 & $7.98 \times 10^{16}$ & $25^{\circ} \mathrm{C}$ \\
\hline $\mathrm{Sr}$ & 400 & $1.36 \times 10^{18}$ & $25^{\circ} \mathrm{C}$ \\
\hline
\end{tabular}

The implantations are being carried out at the University of Michigan by the Michigan Ion Beam Laboratory (MIBL) using a $400 \mathrm{kV}$ inline implanter dubbed "Blue". To implant the specimens, a new sample holder was designed to account for the thin geometry of the samples. The holder was fabricated out of copper and consists of a base with individual sample wells and a top mask to constrain the samples while not applying force to the individual sample. The samples could not be "clamped" down on because of concerns about fracturing. Figure 16 shows the sample holder on the $400 \mathrm{kV}$ inline implanter at MIBL with 13 samples loaded. A total of 30 samples can be implanted simulatenously.

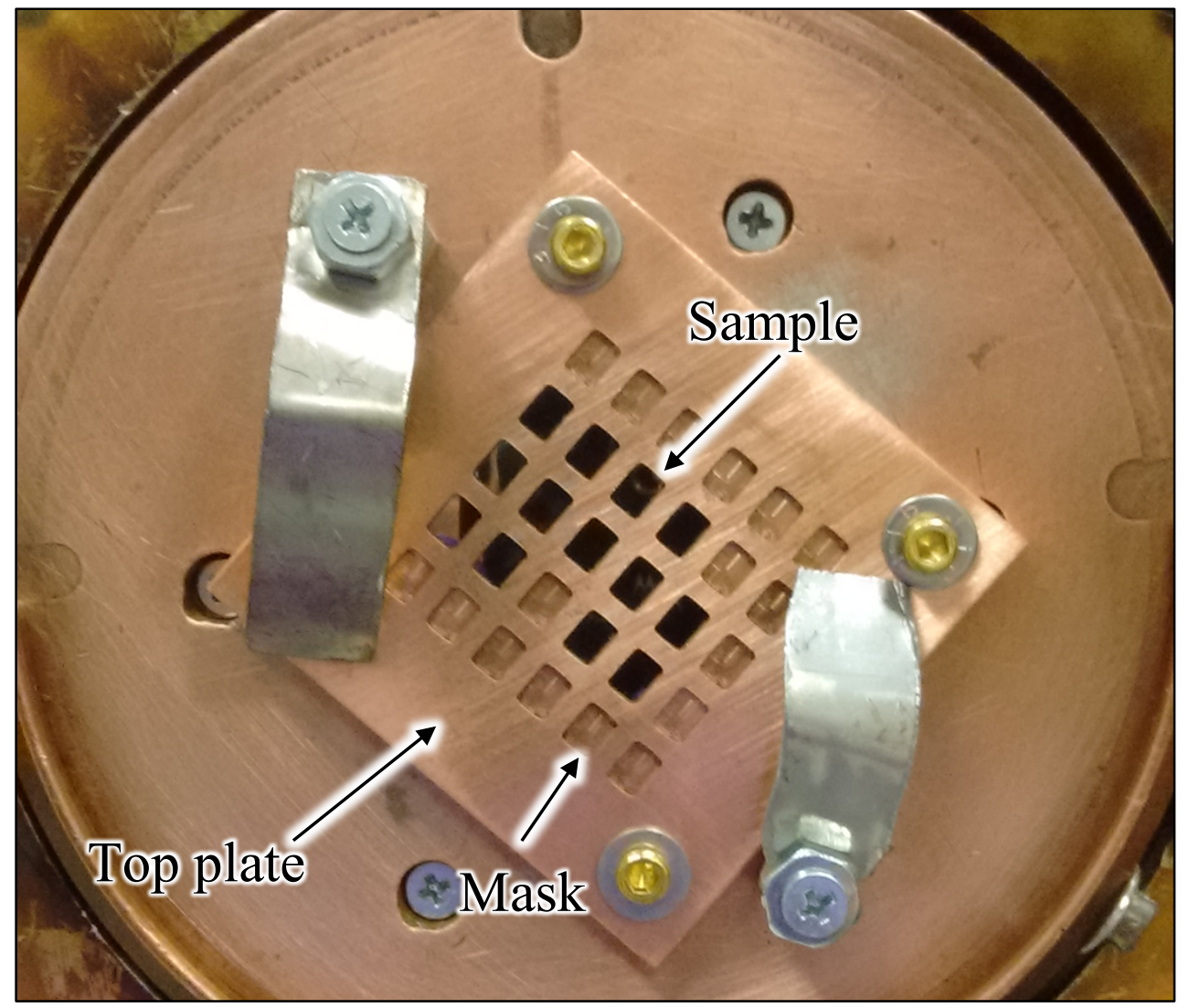

Figure 16. DCCD-06 samples loaded in the $\mathrm{Cu}$ holder on the in-line implanter at MIBL.

The first implantation conducted was the silver implantation into DCCD-06 following the conditions described in Table 9. This represents a test condition to be used for seal coating development and to ensure the implantation approach is acceptable. The silver condition was selected first as the seal coating approach is a high temperature process in which some fraction of the implantation dose is expected to be lost prior to forming a hermetic seal via FBCVD SiC deposition (see Section 4). In particular silver is 
expected to be the fastest diffuser as such is the rate limiting condition when considering loss of the diffusing species during seal coating.

The expected depth profile after ion implantation is estimated from SRIM [27] and shown in Figure 17. A technique which is able to profile 10's of microns is required to measure the concentration profile after implantation and subsequent seal coating to confirm the remaining implanted dose. Two available systems show promise for rapid depth profiling analysis. These techniques include Laser-induced Breakdown Spectroscopy (LIBS) and Glow Discharge Optical Emission Spectroscopy. Both techniques have parts-per-million sensitivity and appropriate depth resolution to analyze the sample depth profiles. Initial tests using LIBS on an as-implanted DCCD-06 sample have shown the ability to resolve the implantation peak as a function of depth. The results are currently being analyzed to generate a depth profile to compare to expected SRIM results.

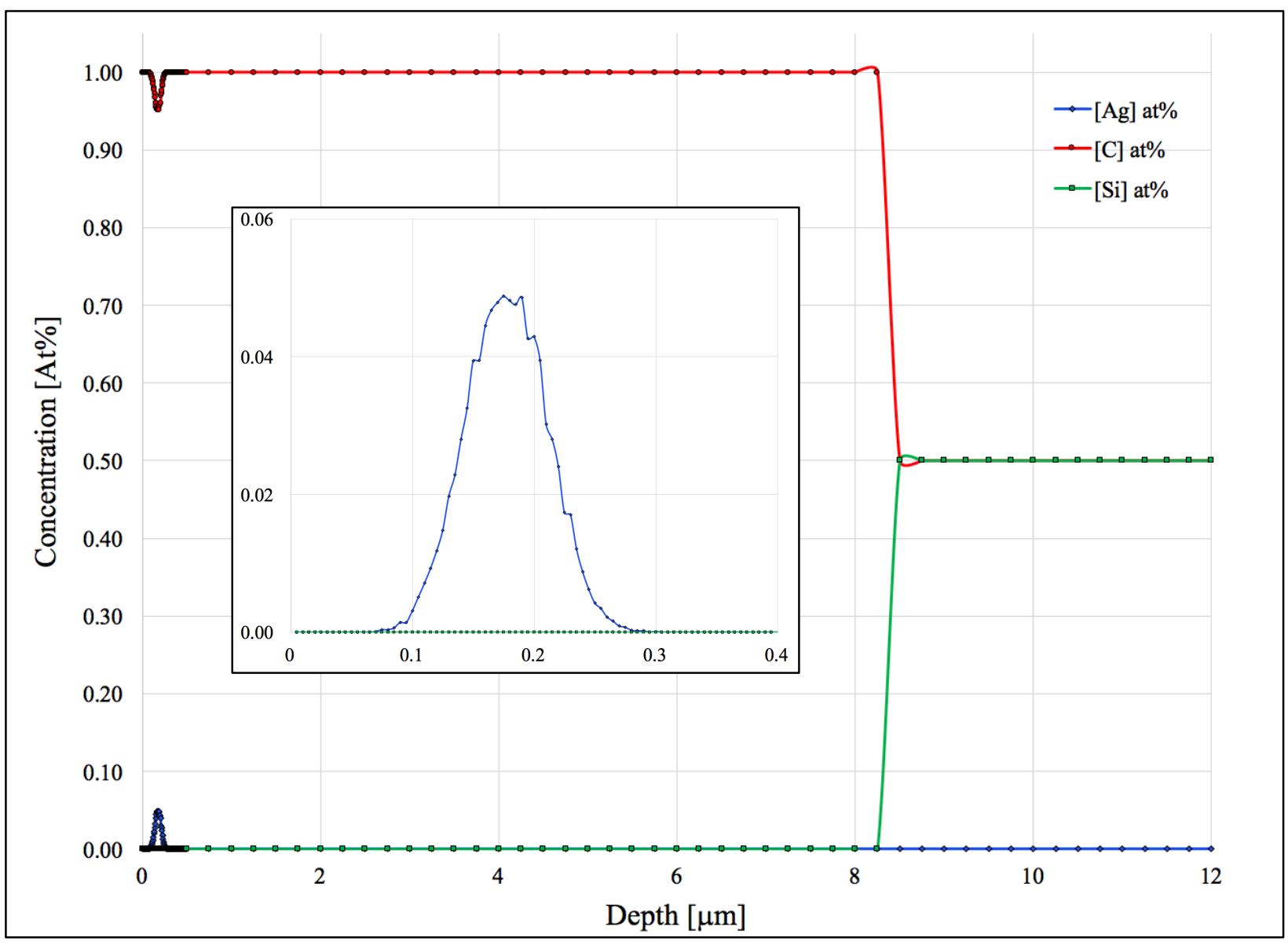

Figure 17. Estimated depth profile for $400 \mathrm{kV}, 4.2 \times 10^{16} \mathrm{ions} / \mathrm{cm}^{2} \mathrm{Ag}^{+}$implantation.

\section{SEAL COATING}

A hermetic seal around the $\mathrm{PyC} / \mathrm{SiC} / \mathrm{PyC}$ layered structure is required to create an isolated system and contain the introduced fission products in the PyC layer. The hermetic seal must also be able to withstand high temperatures and the reactor environment. Additionally, the seal coat provides structural support for 
the samples. The primary approach utilizes a secondary SiC layer as the seal coat and is deposited using the FBCVD reactor.

Seal coating development was conducted on sectioned specimens from DCCD-03 and DCCD-04. Five $\mathrm{PyC} / \mathrm{SiC} / \mathrm{PyC}$ specimens were coated simultaneously which allowed for multiple seal coating runs from each initial sample set. The seal coat runs are described by the initial $\mathrm{PyC} / \mathrm{SiC} / \mathrm{PyC}$ coating run designation (DCCD-\#\#) followed by the sequential seal coating run (-SC\#).

The $\mathrm{SiC}$ seal coat layer was deposited using a similar procedure to what was previously described in Section 2. A change to the process included using $500 \mu \mathrm{m} \mathrm{ZrO}_{2}$ particles as the fluidizing media instead of the $400 \mu \mathrm{m}$ particles used for the sapphire disk coating. Also, prior to introduction of the sectioned specimens to the fluidized bed, a low-density carbon layer was deposited onto the $\mathrm{ZrO}_{2}$ particles to provide a less abrasive surface and avoid damaging the sectioned specimens prior to the $\mathrm{SiC}$ seal coating. A Pyrex funnel was used to direct the sectioned specimens through the site port area of the furnace and into the coating chamber. For the initial seal coating runs, the temperature of the fluidized bed was reduced to below the melting point of Pyrex before introduction of the sectioned specimens. Future seal coating runs will utilize a custom graphite funnel allowing the specimens to be loaded at appropriate $\mathrm{SiC}$ deposition temperatures and minimize the dwell time at temperature prior to $\mathrm{SiC}$ coating.

Table 10. SiC seal coating deposition conditions

\begin{tabular}{cccccccc}
\hline Run & $\begin{array}{c}\text { Run } \\
\text { Time } \\
(\mathbf{m i n})\end{array}$ & $\begin{array}{c}\text { Temp. } \\
\left({ }^{\circ} \mathbf{C}\right)\end{array}$ & Ar & $\mathbf{H}_{2}$ & CGF & $\begin{array}{c}\text { MTS } \\
\text { used }(\mathbf{g})\end{array}$ & $\begin{array}{c}\text { Seal Coat } \\
\text { Thickness }(\boldsymbol{\mu m})\end{array}$ \\
\hline DCCD-03-SC1 & 113 & 1425 & 3500 & 3500 & 0.029 & 160 & $5.9-22.6$ \\
\hline DCCD-04-SC1 & 220 & 1425 & 3500 & 3500 & 0.023 & 241 & $41.1-44.4$ \\
\hline DCCD-04-SC2 & 219 & 1425 & 3500 & 3500 & 0.024 & 250 & $33.2-47.8$ \\
\hline
\end{tabular}

The seal coated samples were exposed to elevated temperatures for $900{ }^{\circ} \mathrm{C}$ for 5 hours in air to test for a hermetic seal. If the $\mathrm{SiC}$ seal coating is compromised the $\mathrm{PyC}$ and $\mathrm{S}-\mathrm{PyC}$ will be burned out similar to the observations during the burn stage of leach-burn-leach analysis.

The coating from DCCD-03-SC1 failed to maintain a hermetic seal. Failure was determined by measurement the weigh change after the burn stage for DCCD-03-SC1. All samples from DCCD-03-SC1 showed weight loss proportional to the amount of $\mathrm{PyC}$ in the samples and failure was confirmed by optical microcopy. It was assumed that the coating did not provide sufficient coverage or may have cracked during handling as a result of the use of tweezers. The cracking was assumed to be the likely cause of failure because of the thin nature of the seal coat. All specimens after DCCD-03-SC1 were handled using vacuum tweezers to avoid introducing possible fracture to the thin, coated samples.

Seal coating of DCCD-04-SC1 and DCCD-04-SC2 showed significant improvement. An additional support PyC layer was introduced to the DCCD-04 seal coating runs. This layer was deemed to not add any sufficient value as the SiC only seal coating is assumed to provide sufficient support therefore it will not be deposited in future runs. After the seal coating only $40 \%$ of the seal coated diffusion couple specimens were recovered. The remainder was stuck to the side of the cone near the nozzle inlet. The specimens that were recovered were subjected to the burn step. Figure 18 shows the cross-section of a DCCD-04-SC2 sample subjected to the $900{ }^{\circ} \mathrm{C}, 5$ hour burn in air. The sample shows both the PyC and S-PyC layer remained intact. All specimens' subjected to the burn step from DCCD-04-SC1 and DCCD-04-SC2 survived the burn stage implying they retained their hermetic seal. This provides confidence in this approach to create an isolated system to analyze diffusion in the $\mathrm{PyC} / \mathrm{SiC}$ system. 


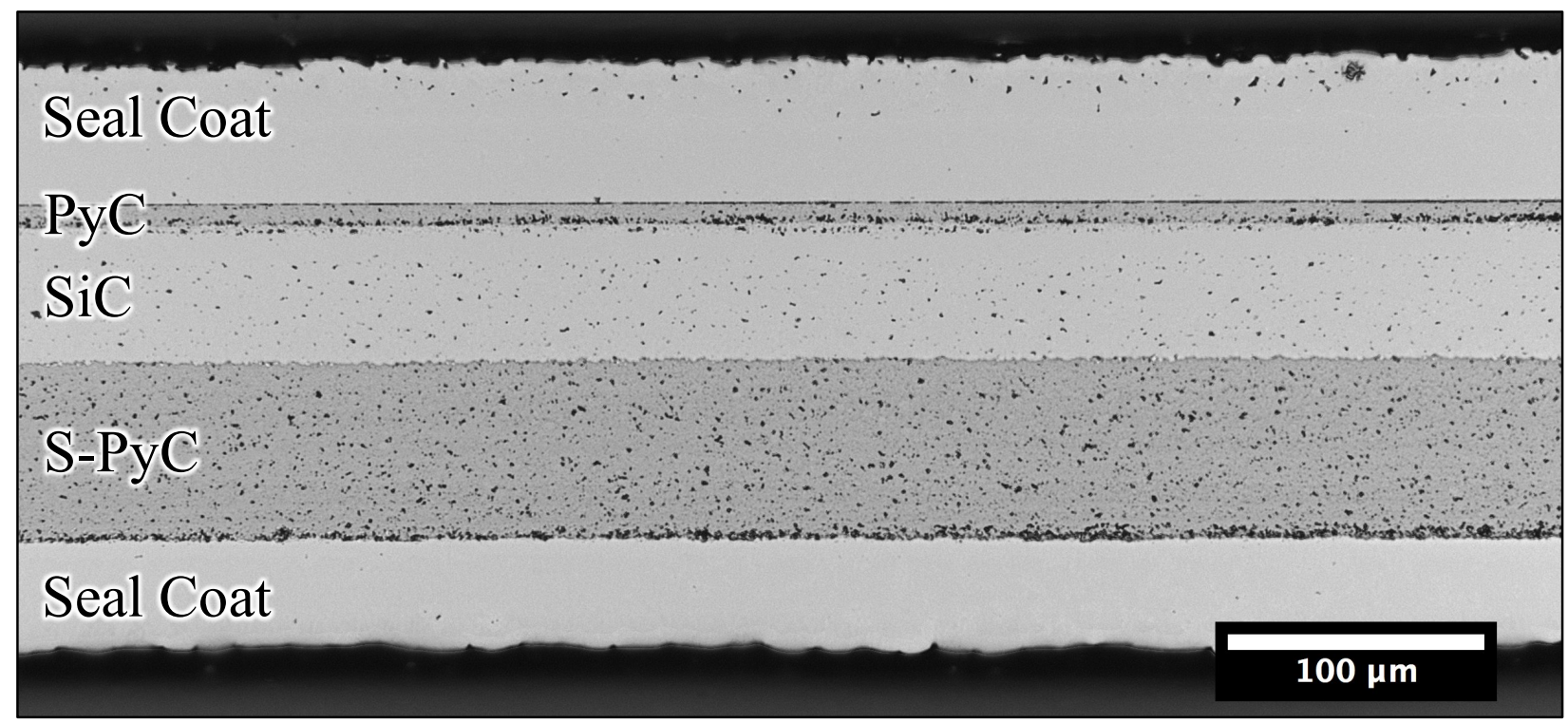

Figure 18. Optical image of DCCD-04-SC2 subjected to $900{ }^{\circ} \mathrm{C}$ for 5 hours.

The pinning of the samples to the edge of the nozzle will limit the yield during seal coating. The nozzle with the attached samples was extracted and subjected to a burn step to isolated the samples and attempt to determine when the samples were attached to the nozzle. After the burn step the samples remained attached to the deposited material while the graphite of the nozzle was burned away. The remaining material was placed in an epoxy mount in a position to provide a cross-section of the three seal coated diffusion couple specimens. The samples from the polished cross-section are shown in Figure 19.
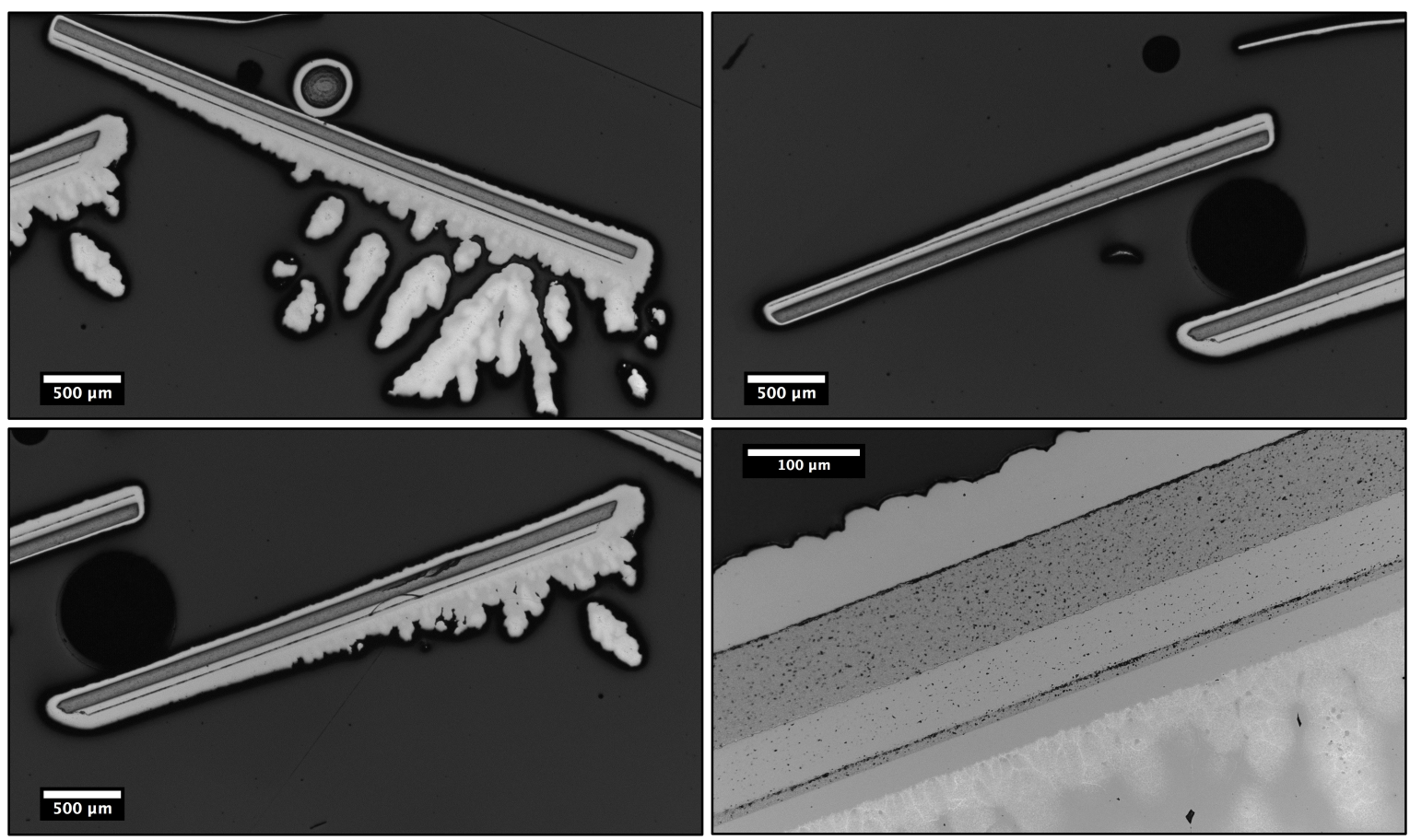

Figure 19. Optical images of the samples after the burn and remaining in the deposited material at the nozzle. 
The cross-sectioned samples confirm the samples were immobilized during the SiC deposition stage. The thicknesses of the $\mathrm{SiC}$ seal coatings on the three "stuck" samples before the irregular deposition occurred were approximately $28 \mu \mathrm{m}, 23 \mu \mathrm{m}$, and $30 \mu \mathrm{m}$. This suggests the samples were trapped later in the seal coating process as the thickness of the seal coat layer for the two other samples ranged from 32 to $41 \mu \mathrm{m}$. Particles becoming pinned near the cone inlet typically isn't a problem, however, the flat geometry of the samples to be seal coated seems to increase their susceptibility to becoming pinned. To mitigate this issue, further study of the deposition conditions and furnace set up will occur. Initially, total batch size will be reduced to increase relative movement of the samples throughout the fluidized bed. If necessary, a modified coating chamber, specific to the seal coating process, will be fabricated to have a much steeper (more acute) cone angle promoting movement of the samples toward the inlet thereby reducing the chance of the samples sticking to the coating chamber wall. If the issue cannot be resolved through modified deposition conditions or coating chamber geometry, shortening the deposition run time should limit the probability of trapping samples.

Analysis of the remaining implantation dose after seal coating will be performed to validate the seal coating approach because the seal coating is a high temperature process and some loss of implanted species is expected. The final distribution of the implanted species after the seal coating is considered the initial condition for diffusion analysis and diffusion will be investigated by measuring the change in concentration profiles at multiple time steps for thermally exposed specimens. The planned approach for the seal coating of implanted specimens is to perform the standard SiC seal coating deposition described earlier, however, the specimens will be introduced to the fluidized bed at temperature to rapidly initiate $\mathrm{SiC}$ deposition. If this approach is not successful secondary approaches will be pursued, however, the pure $\mathrm{SiC}$ deposition is the primary target as the introduction of a barrier layer with irregular properties is undesirable as a different material may act as a sink for the diffusion species. One potential alternative approach is the use of polycarbosilane to deposit a low temperature $\mathrm{SiC}$ layer. Other lower temperature deposition barrier layers may also be considered. Additionally, if some remaining fraction of implanted species remains after seal coating the implantation dose can be increased to scale the remaining concentration. This is the ideal alternative approach, as it does not introduce a possible sink material. Seal coating with the silver implanted samples from DCCD-06 is the next step in the development process.

\section{IRRADIATION DESIGN}

In depth details of the capsule design can be found in ORNL/TM-2017/390, "Design and Thermal Analysis for Irradiation of Pyrolytic Carbon/Silicon Carbide Diffusion Couples in the High Flux Isotope Reactor" [28]. An overview of the design and its impact on the PyC/SiC diffusion couple development is summarized here.

A schematic of the irradiation capsule design is shown in Figure 20. The capsule design utilizes a sealed rabbit housing compatible with the HFIR. The primary component of the capsule pertaining to the $\mathrm{PyC} / \mathrm{SiC}$ specimen design is the central graphite container. This graphite container consists of four thin slots to house the thin geometry $\mathrm{PyC} / \mathrm{SiC}$ diffusion couple specimens. The size of the internal components are limited as the temperature of the capsule is controlled the gas gap. This constrains the ultimate dimensions of the samples and requires the width of the sample be $3.0 \mathrm{~mm}$ to provide tolerance in the loading. The design as shown, allows for a maximum of 40 samples to be irradiated in each capsule. 


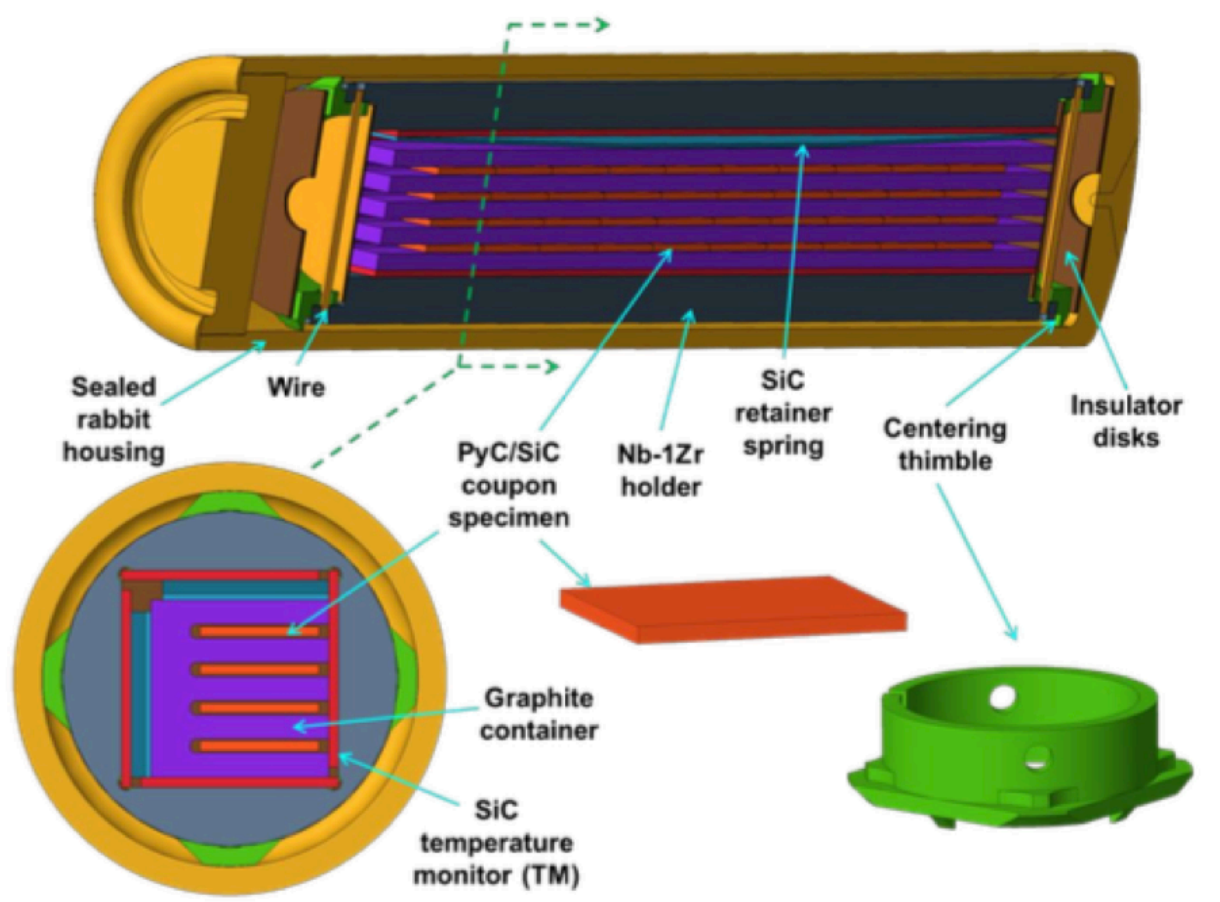

Figure 20. Section view of capsule design and components, reproduced from Petrie et.al. [28].

Thermal analysis shows that the target temperature of $1100^{\circ} \mathrm{C}$ can be achieved. The results of the thermal analysis are shown in Figure 21. The primary heat generation is provided by the capsule components and not the specimens because of their small volume. The design equates to an approximately $46{ }^{\circ} \mathrm{C}$ range in temperatures for the specimens with an average specimen temperature of $1120^{\circ} \mathrm{C}$. The temperature of the system is monitored post irradiation by four $\mathrm{SiC}$ temperature monitors surrounding the graphite capsule. These SiC temperature monitors will be analyzed after the irradiation by SiC thermometry to determine the operational temperature of the system [29].

The capsule design allows for the goals of the experiment to be accomplished while working within the constraints of the $\mathrm{PyC} / \mathrm{SiC}$ coating system. The design is particularly ideal in that there is a limited temperature gradient across the $\mathrm{PyC} / \mathrm{SiC}$ diffusion couple specimen, which is ideal for diffusion analysis. The graphite container is currently being machined to test the fit of the system prior to complete construction of the design. 

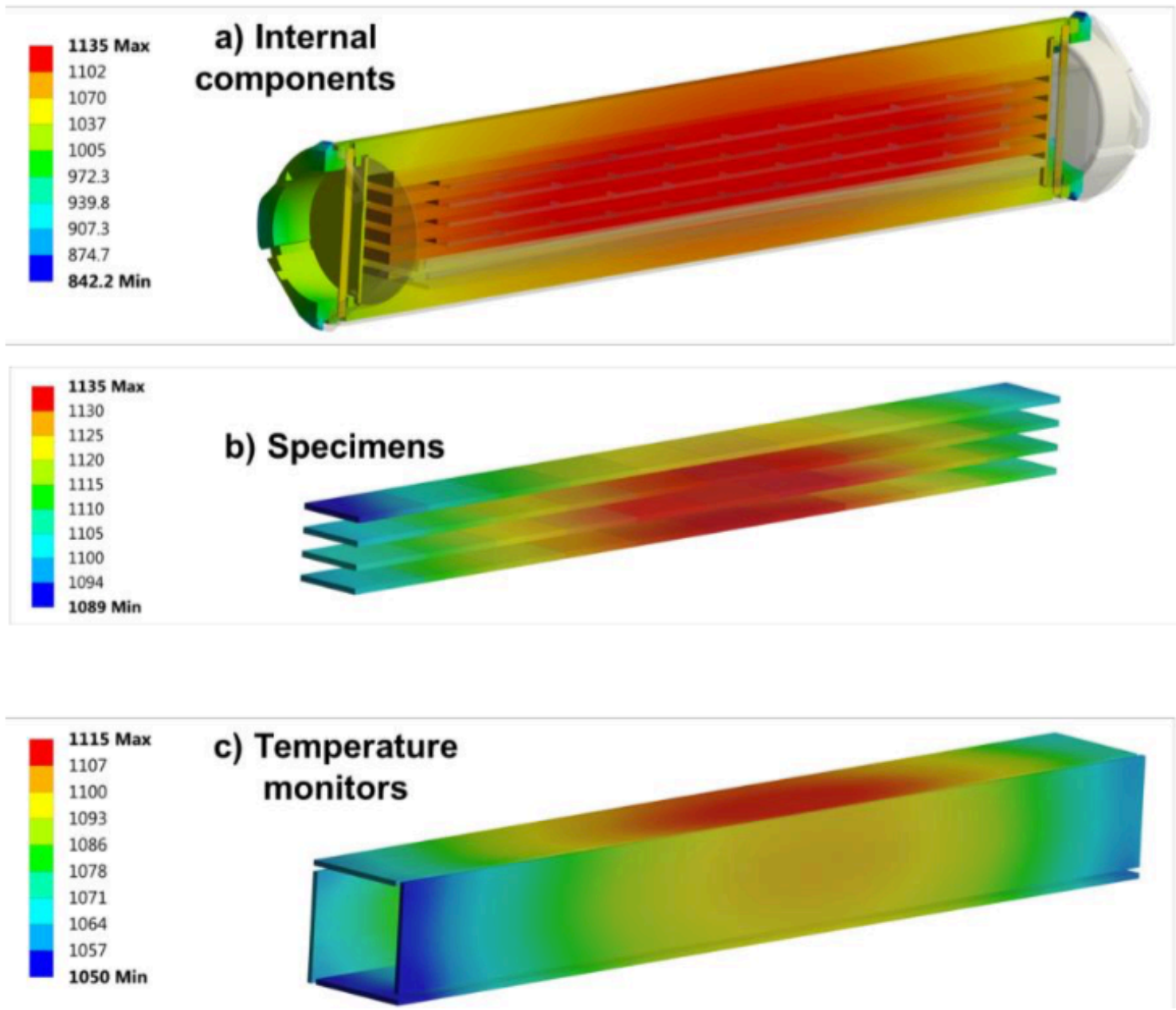

Figure 21. Thermal analysis results showing temperature contour profiles for (a) the internal components, (b) specimens, and (c) SiC temperature monitors, reproduced from Petrie et.al. [28].

\section{SUMMARY}

A process for fabrication of planar $\mathrm{PyC} / \mathrm{SiC}$ diffusion couples has been demonstrated along with the methodology for characterizing the layer properties. The fabrication approach built off of process knowledge acquired during the coating efforts for AGR-1 and AGR-2 TRISO fuel development. The final construction and geometry was based on the ability to fluidize large disks, handle the samples, and the constraints from the irradiation capsule design. The thin geometry proved to have some benefits considering the irradiation component of the experiment, as the thin geometry limits thermal gradients across the specimen.

The coating conditions to produce the appropriate layer properties for the $\mathrm{PyC} / \mathrm{SiC}$ diffusion couple specimens required significant development, which is ongoing. The fabrication conditions to achieve the appropriate PyC layer density for all diffusion couple variants are defined through systematic study, however, the PyC anisotropy remains in question. Ultimately, the PyC density is considered the critical design criteria. The initial anisotropy sample was not ideal and an better measuring approach may 
improve the outcome. Refinement of the $\mathrm{SiC}$ deposition process is required, as non-ideal porosity was observed and a deviation from optimal grain size was measured by EBSD on initial coating runs. Improvement on $\mathrm{SiC}$ layer porosity has been shown in the comparison from DCCD-04 and DCCD-06 indicating improved $\mathrm{SiC}$ porosity can be achieved in future runs. Improvement on the targeted grain size also remains a requirement. An informed path forward is defined to improve the $\mathrm{SiC}$ coating properties, notably through adjustment of the deposition temperature and precursor concentration. The SiC density will be measured on optimized SiC layers to confirm the targeted density has been achieved.

A sample holder for ion implantation of the thin geometry PyC/SiC specimens was designed and machined. Introduction of silver, the fastest diffusing fission product species, through ion implantation has been successfully demonstrated. The appropriate ion implantation dose for each condition will be confirmed after refinement of the seal coating process. The seal coating process has demonstrated the ability to allow the specimens to withstand elevated temperature and that the seal coat yields a hermetic seal to create an isolated system for diffusion analysis. Refinement of the seal coating technique is required to avoid sample trapping in the coater nozzle. The ability to retain the implanted dose after seal coating remains to be confirmed and is expected to be a primary challenge in the diffusion couple development. 


\section{REFERENCES}

1. Demkowicz, P.A., J. D. Hunn, R. N. Morris, I. van Rooyen, T.J. Gerczak, J. M. Harp, S.A. Ploger, AGR-1 Post Irradiation Examination Final Report. INL/EXT-15-36407, 2015. Idaho Falls: Idaho National Laboratory.

2. Malherbe, J.B., Diffusion of fission products and radiation damage in SiC. Journal of Physics D: Applied Physics, 2013. 46(47): p. 473001.

3. Kim, B.G., et al., Comparison of diffusion coefficients and activation energies for Ag diffusion in silicon carbide. Nuclear Engineering and Technology, 2015.

4. van Rooyen, I.J., M.L. Dunzik-Gougar, and P.M. van Rooyen, Silver (Ag) transport mechanisms in TRISO coated particles: A critical review. Nuclear Engineering and Design, 2014. 271: p. 180188.

5. Olivier, E.J. and J.H. Neethling, The role of Pd in the transport of Ag in SiC. Journal of Nuclear Materials, 2013. 432(1-3): p. 252-260.

6. Neethling, J.H., J.H. O'Connell, and E.J. Olivier, Palladium assisted silver transport in polycrystalline SiC. Nuclear Engineering and Design, 2012. 251: p. 230-234.

7. Brown, P.E. and R.L. Faircloth, Metal fission product behaviour in high temperature reactors UO2 coated particle fuel. Journal of Nuclear Materials, 1976. 59: p. 29-41.

8. Nabielek, H., P.E. Brown, and P. Offerman, Silver release from coated particle fuel. Nuclear Technology, 1977. 35(2): p. 483.

9. Friedland, E., et al., Study of silver diffusion in silicon carbide. Journal of Nuclear Materials, 2009. 389(2): p. 326-331.

10. Friedland, E., et al., Investigation of silver and iodine transport through silicon carbide layers prepared for nuclear fuel element cladding. Journal of Nuclear Materials, 2011. 410(1-3): p. 2431.

11. López-Honorato, E., et al., Silver Diffusion in Coated Fuel Particles. Journal of the American Ceramic Society, 2010. 93(10): p. 3076-3079.

12. Hlatshwayo, T.T., et al., Annealing of silver implanted $6 \mathrm{H}-\mathrm{SiC}$ and the diffusion of the silver. Nuclear Instruments and Methods in Physics Research Section B: Beam Interactions with Materials and Atoms, 2012. 274: p. 120-125.

13. MacLean, H.J., et al., The effect of annealing at $1500^{\circ} \mathrm{C}$ on migration and release of ion implanted silver in CVD silicon carbide. Journal of Nuclear Materials, 2006. 357(1-3): p. 31-47.

14. Xiao, H.Y., et al., Near-surface and bulk behavior of $\mathrm{Ag}$ in SiC. Journal of Nuclear Materials, 2012. 420(1-3): p. 123-130.

15. Amian, W. and D. Stover, Diffusion of silver and cesium in silicon-carbide coatings of fuel particles for high temperature gas-coolcd reactors. Nuclear Technology, 1983. 61(3): p. 475.

16. Bullock, R.E., Fission-product release during postirradiation annealing of several types of coated fuel particles. Journal of Nuclear Materials, 1984. 125: p. 304-319.

17. van der Merwe, J.J., Evaluation of silver transport through SiC during the German HTR fuel program. Journal of Nuclear Materials, 2009. 395(1-3): p. 99-111.

18. Gerczak, T.J., et al., Observations of Ag diffusion in ion implanted SiC. Journal of Nuclear Materials, 2015. 461: p. 314-324.

19. Leng, B., et al., Effect of carbon ion irradiation on Ag diffusion in SiC. Journal of Nuclear Materials, 2015. 471: p. 220-232.

20. Dwaraknath, S. and G.S. Was, Development of a multi-layer diffusion couple to study fission product transport in $\beta$-SiC. Journal of Nuclear Materials, 2014. 444(1-3): p. 170-174.

21. Morris, R.N., et al., Performance of AGR-1 high-temperature reactor fuel during post-irradiation heating tests. Nuclear Engineering and Design, 2016. 306: p. 24-35.

22. Collin, B.P., AGR-2 Irradiation Test Final As-Run Report. INL/EXT-14-32277, Revision 3, 2017. Idaho Falls: Idaho National Laboratory. 
23. Gerczak, T.J., et al., SiC layer microstructure in AGR-1 and AGR-2 TRISO fuel particles and the influence of its variation on the effective diffusion of key fission products. Journal of Nuclear Materials, 2016. 480: p. 257-270.

24. Kirchhofer, R., et al., Microstructure of TRISO coated particles from the AGR-1 experiment: SiC grain size and grain boundary character. Journal of Nuclear Materials, 2013. 432(1-3): p. 127134.

25. van Rooyen, I.J., et al., Electron microscopic evaluation and fission product identification of irradiated TRISO coated particles from the AGR-1 experiment: A preliminary review. Nuclear Engineering and Design, 2014. 271: p. 114-122.

26. Sterbentz, J.W., JMOCUP As-Run Daily Depletion Calculation for the AGR-2 Experiment in ATR B-12 Position. ECAR-2066, 2014. Idaho Falls: Idaho National Laboratory.

27. Ziegler, J.F., M.D. Ziegler, and J.P. Biersack, SRIM - The stopping and range of ions in matter (2010). Nuclear Instruments and Methods in Physics Research Section B: Beam Interactions with Materials and Atoms, 2010. 268(11-12): p. 1818-1823.

28. Petrie, C.M., Smith, K., Gerczak, T.J., Design and thermal analysis for irradiation of pyrolytic cabon/silicon carbide diffusion couples in the high flux isotope reactor. ORNL/TM-2017/390, 2017. Oak Ridge: Oak Ridge National Laboratory.

29. Campbell, A.A., et al., Method for analyzing passive silicon carbide thermometry with a continuous dilatometer to determine irradiation temperature. Nuclear Instruments and Methods in Physics Research Section B: Beam Interactions with Materials and Atoms, 2016. 370: p. 49-58. 